\title{
International production networks and the world trade structure
}

\author{
Isabella Cingolani ${ }^{\mathrm{a}}$, Lelio Iapadre ${ }^{\mathrm{b}}$ Lucia Tajoli $^{\mathrm{c}}$ \\ ${ }^{a}$ Big Data and Analytical Unit, Institute of Global Health Innovation, Imperial College London, London, UK \\ ${ }^{\mathrm{b}}$ Dipartimento di Ingegneria Industriale e dell'Informazione e di Economia, Università de L'Aquila, Italy \\ ${ }^{\mathrm{c}}$ Department of Management, Economics, and Industrial Engineering, Politecnico di Milano, Italy
}

\section{ABSTRACT}

In this work, we examine bilateral trade data in two industries with different technological characteristics (textiles and apparel, and electronics) in order to detect the presence of interna-tional production networks in these sectors and to assess their structures and organization. Moving from the recent stream of literature that underlines the importance of assessing the participation and position of a country within an international production system, generally much more com-plex than a simple chain, we examine if these networks can be identified using traditional trade data and if they are still mainly regional.

We start by applying a particular specification of bilateral trade intensity indices to the matrix of world trade in each sector (from the BACI - CEPII database), using the BEC classification to dis-tinguish between intermediate and final goods, in order to highlight trade flows driven by international production networks. We compute indicators for the world trade matrix and its regional partitions, as defined by exogenous geographical criteria, or by the existence of regional integration agreements. The resulting pattern of revealed trade preferences conveys useful information about the actual geographic distribution of the underlying international value chains. The core of the paper is an application of network analysis to better understand the topology of global and regional value chains. In each industry, we identify endogenous geographical sub-networks based on preferential trade links, again distinguishing between trade flows in intermediate or final goods, and we examine the topological structure of the trading regions, to assess whether they are similar across industries and goods' categories, and if they are built around a central core country.

On the basis of both approaches, we conclude that trade regionalization is still high, especially in electronics, confirming that geographical proximity and other integration factors still play a role in facilitating international production and trade. However, regionalization has slightly declined in the recent past, and there are some relevant preferential linkages bridging different regions.

In addition, the topology of trade networks can indeed shed some light on the structure of the underlying production linkages. In particular, a stronger preferentiality and selection of partners seem to occur for trade in intermediate goods, as suggested by the theory of international fragmentation of production.

\section{Introduction}

International production linkages, giving rise to new types of specialization and vertical relations between countries, are certainly among the main features characterizing the pattern of trade flows in the recent past. Global value chains (GVCs) arise as a consequence of this international fragmentation of production, the process by which the different phases of the production process of a final good are undertaken in different countries to exploit the specific comparative advantage of each location. 
The growth of international production networks has been driven by different motivations following sector characteristics. In traditional labour-intensive sectors, vertical production links were created mainly by developed countries' firms moving production phases from North to South (e.g. between the United States and Mexico), or from West to East (e.g. in the case of Europe) to exploit differences in factor costs (Hanson, 1996, 1998; Baldone et al., 2001). In advanced sectors, such as automobiles and electronics, the search for appropriate technologies and large markets has fostered North-North production linkages based mainly on foreign direct investment (FDI). Over time, the geography of GVCs has become much more intricate, involving also international outsourcing, and nowadays the manufacture of highly complex goods often relies on components made in a number of advanced countries, connected through a web of production linkages (Spencer, 2005; Nunn, 2007). Emerging countries started as well to delocalize production phases towards other developing countries, and there is evidence of some re-insourcing taking place (Drauz, 2014). The evolution in the span of GVCs and their geographic scope stirred a debate in the literature, also on the possibility that they reached a plateau in their extension (Los et al., 2015; Timmer et al., 2016).

In many sectors, advances in communication and transportation technologies allowed GVCs to stretch at much larger distances, moving from a regional to a global dimension. Moreover, important trade policy changes at the multilateral level, following the Uruguay Round of trade negotiations, contributed to reshaping the geography of international production networks, by further reducing trade costs on a global scale, like in the case of the Multifibre Agreement dismantling. On the other hand, various factors, including pref-erential trade agreements and distance-related trade costs, can still limit the actual geographic scope of value chains. Therefore, the simple view of production delocalization often within a given region is certainly outdated, and replaced by a system of more complex and extended relations, sometimes named global production networks (Henderson et al., 2002; Yeung and Coe, 2015).

In this paper, we want to understand to what extent international production networks (IPNs) affect the structure and patterns of international trade. Given that the motivations and bases of trade in tasks and parts are to some extent different from those of final goods (Grossman and Rossi-Hansberg, 2008), we expect to observe these differences in the trade structure.

More specifically, we address the following questions: are IPNs regional or global? Are trade structures similar across industries affected by international fragmentation of production? Are these structures centralized or scattered uniformly across countries? Is there more selectivity in the choice of partners for production links than for trade in final goods? Models of international fragmentation of production suggest that organizational and transaction costs can be high for this type of transactions (Antràs and Helpman, 2004), and therefore we expect distance (not only in geographical terms) and the choice of partners to be even more relevant in IPNs. If this is true, more selectivity and more regionalization (as suggested, by Baldwin, 2011) should be observed in trade driven by IPNs, and trade patterns should be built around central nodes organizing the production process.

It is important to shed some light on the overall geography of IPNs and their structure for a number of reasons. First of all, pricing decisions, employment and the distribution of value added linked to these production processes are affected by their structure (Costinot et al., 2013). Furthermore, the geography of IPNs affects the scope of shock transmission and business cycle co-movements (di Giovanni and Levchenko, 2009; $\mathrm{Ng}, 2010$; Carvalho, 2014). But so far, the empirical evidence still conveys an unclear portrait of world trade in presence of IPNs, as methods to detect IPNs through trade data are still debated (Baldwin and Lopez Gonzalez, 2015; De Backer and Miroudot, 2013).

This paper aims at filling at least in part this gap, by combining different methodologies to detect IPNs and taking a closer look to their topology and structure to address the questions raised above.

We start by assuming that international production linkages among countries make their reciprocal trade more intense than it would be otherwise, giving rise to bilateral 'revealed trade preferences' observable in the data, and we examine the pattern of these preferences for different groups of countries. We then apply social network analysis of complex systems to study the topology of the resulting preferential trade networks. The analysis of the network of trade preferences allows to consider the world trading system as a whole and to evaluate preferentiality with respect to the entire set of potential production relations.

In the world network that we analyse, each country is a node, and trade flows are the links between nodes. However, unlike in previous applications of network analysis to trade, we do not consider simply the existence or the value of bilateral trade flows among countries, but we restrict the analysis to networks identified by indices of revealed trade preferences, as defined in Section 3 . Therefore, in our network there is a link between two nodes (countries) if there is a preferential trade link between the two, which can be an important indicator of the presence of an international production network. Furthermore, to better detect production-related trade, we distinguish between preferential trade networks in intermediate and final goods, also because we expect to see differences between the two cases, if firms and countries are more selective in choosing partners when creating production linkages than when selling final goods on a market, as suggested by trade theory. We limit the analysis to two different industries (textiles and apparel, and electronics), chosen because they are presented in other studies as very involved in IPNs (De Backer and Miroudot, 2013) and the specific characteristics of the production process can influence the observed trade structure. The industries considered differ in terms of technological content, maturity, and in terms of input and headquarter services intensity.

We expect to find highly non-random structures in particular when trade links are the display of an underlying international production process, where different countries play a specific role in the organization of production. Therefore, different network structures should be associated to the exchange of intermediate inputs rather than of final goods, assuming that the existence of long production chains, or production networks, stretching across many countries, is giving rise to these trade flows. In general, we expect more preferentiality in intermediate goods trade than in final goods.

\section{Literature review}

Previous works applying network analysis to international trade shed light on a number of relevant characteristics of the structure of 
exchanges between countries (De Benedictis and Tajoli, 2011). Analyses undertaken at the sectoral level (De Benedictis and Tajoli, 2010; De Benedictis et al., 2014; Cingolani et al., 2015) show that the international trade networks formed by trade links in distinctive industries display quite different characteristics. For example, there are industries with a relatively higher network density, and industries with a much lower density, industries where it is common to observe communities of countries and other where these structures are less frequent. Such characteristics appear to be related to the type of goods traded, to the international organization of production of such goods, and to the specific features of demand and supply in these markets.

Network analysis also allows comparing the different structure of regional trading clusters (Iapadre and Tajoli, 2014), showing that regional groups tend to display asymmetric structures, with a core and a periphery. It is not surprising to observe these peculiar features: economic networks, differently from random networks, should arise because of the effects of cooperative or competitive forces at work between units of the network, which influence its structure (Vega Redondo, 2007; Jackson, 2014). A random distribution of linkages between countries and a random structure is therefore very unlikely.

Until now, network analysis has been only rarely applied to the study of international production networks. Instead, several other methods are being used to identify and measure the growth of international production along increasingly global networks. One simple approach is based on the idea that the functioning of international production networks generates increasing flows of trade in inputs. So, the first phase of the empirical literature on the international fragmentation of production is based on the study of trade in intermediate goods (Arndt and Kierzkowski, 2001). According to De Backer and Miroudot (2013), intermediate inputs account for about 50 per cent of world trade in goods and 70 per cent in services. The main problem with the trade-data approach is that it depends on the quality of the classification used to identify intermediate goods.

A second, increasingly popular, approach builds on a system of input-output tables, interlinked by trade data. The first attempt to use input-output tables to overcome the limitations of the trade data approach is due to Hummels et al. (2001). More recently, this methodology has been developed thanks to the availability of new sets of inter-country input-output tables, and new analytical tools (Koopman et al., 2014; Timmer et al., 2014) and also the issue of the geographic scope of IPNs has been address using this type of measurement (Los et al., 2015). The main advantage of this approach is that it allows to estimate international links in terms of countries' contribution to the value added of the traded goods, eliminating the problem of double-counting (Johnson and Noguera, 2012).

Thirdly, statistics on the ownership structure and activities of trans-national enterprises can be used to represent international production. Examples include Hanson et al. (2005) and Kimura and Ando (2003). However, the resulting picture inevitably neglects the role of cooperation agreements among independent firms, as well as cases in which vertical fragmentation of production is implemented through arms' length transactions.

A fourth strand of literature relies on case studies, that allow to study in detail the organization of production networks, but give results that are difficult to generalize.

So, a comprehensive and reliable representation of international production networks can only be pursued by considering multiple approaches. This paper aims to further expand the toolset available to understand IPNs by experimenting new statistical techniques, based on network analysis, to detect traces of international production networks in trade data. Therefore, this work is connected to the first strand of literature mentioned, based on trade in intermediate inputs, but it is novel in terms of the methodology used to analyse these data. The advantage of pursuing the analysis using the well-known gross trade datasets is the possibility to have a full detailed coverage of all countries in the world. The potential double-counting of the value of international transactions is not a major problem here, because the purpose of the analysis is not to identify a country's specialization or its specific contribution to international trade in a given industry, but rather the strength of the existing links between countries. In this case, even back-and-forth movements of a good between a pair of countries are useful to identify the presence of strong ties between them.

\section{Data}

The trade data used come from the BACI database developed by the Centre $\mathrm{d}^{\prime}$ Etudes Prospectives et $\mathrm{d}^{\prime}$ Informations Internationales (CEPII), using the United Nations COMTRADE dataset (Gaulier and Zignago, 2010), and refer to the textile and apparel, and to the electronics industries, which are among the ones generally found to have the largest presence of GVCs (De Backer and Miroudout, 2013). We disaggregate these industries following the Broad Economic Categories (BEC) classification, that allows to identify separately intermediate and consumer goods. ${ }^{1}$ This is important to distinguish between trade links related to participation in production-sharing agreements and GVCs, generating sales of intermediate goods, and trade links created to export a final good in a given market. This distinction is imperfect, as final goods can be re-exported to the country from which intermediate goods where imported as the last step of a production chain, and our data do not allow to capture these cases. Also, trade in capital goods can be considered as final trade or as part of an international production chain. In spite of these problems, this is the only dataset allowing a worldwide coverage, which is important to assess the geography of IPNs.

Using trade data for two specific industries, we are defining international production links in a "narrow" sense (see Feenstra and Hanson, 1999), rather than a broad one, considering in the analysis only inputs coming from the same sector. Even if this "conservative" approach might restrict our picture of IPNs, at the same time it allows to consider links that are more likely to represent steps of a specific

\footnotetext{
1 The BACI dataset at a six-digit level was re-aggregated to obtain the goods classification by Broad Economic Categories following the official conversion tables provided by the U.N. The matching between the two classifications is imperfect, and it might be difficult in some cases to classify a specific HS category as intermediate or final. Rather than introducing arbitrary amendments, we have chosen to stick to the official international classifications, so that the possible errors are transparent.
} 


\begin{tabular}{|c|c|c|c|c|}
\hline & \multicolumn{2}{|c|}{ Electronics } & \multicolumn{2}{|c|}{ Textiles } \\
\hline & 2007 & 2014 & 2007 & 2014 \\
\hline Intermediate goods & 0.62 & 0.64 & 0.50 & 0.43 \\
\hline Consumption goods & 0.51 & 0.48 & 0.35 & 0.31 \\
\hline Total trade & 0.55 & 0.55 & 0.41 & 0.36 \\
\hline
\end{tabular}

production process, rather than including the mere purchase of inputs on the international markets.

Our analysis has been performed for the most recent available year (2014) and for the year 2007, in order to see the changes occurred during the global economic crisis.

Before computing the indices, the dataset was filtered, so as to drop from the world trade network the countries with fewer links and remove some of the "noise" in the data. Specifically, countries falling in the lowest 25th percentile of the links' distribution were removed, eliminating a set of small economies with very sparse and irregular trade links, amounting globally to less than $0.1 \%$ of world trade. The filtered network was built for total trade for each of the industries considered, for each category of goods within each industry, and for the world as a whole, as well as for ten regional groupings, as described in Annex 1.

\section{Trade regionalization and international production networks in the electronics and textile industries}

One simple way to assess the aggregate degree of trade regionalization at the global level is by computing the ratio between the total value of intra-regional trade flows and world trade. The result is affected by the initial choice regarding the grouping of countries into regions, but can be taken as a reasonable starting point of our analysis.

Table 1 compares the intra-regional share of world trade across industries and economic categories between 2007 and 2014 . It is clear that trade regionalization is substantially higher in electronics than in textiles, as well as in intermediate goods than in consumption goods. During the global crisis, trade regionalization has slightly fallen, following a trend already visible in the previous decade. The only exception are intermediates in electronics, suggesting the idea that the manufacturing core of GVCs in this sector has become more regionalized. ${ }^{2}$

At the regional level, trade regionalization can be properly assessed with the help of bilateral revealed trade preference (RTP) indicators, which can be aggregated into regional trade introversion indices (Iapadre and Tajoli, 2014). RTP indices belong to the class of statistical indicators aimed at measuring the intensity of bilateral trade. More precisely, they measure to what extent the intensity of trade between two countries differs from the geographic neutrality benchmark based on their relative importance in world trade. RTP indices range from minus one (no bilateral trade) to one (only bilateral trade) and are equal to zero in the case of geographic neutrality. At the regional level, they can be used to measure in relative terms to what extent a region's member countries tend to trade among each other more intensively than with third countries (regional trade introversion). This name is because a high level of intra-regional RTP is often the result not so much of a high degree of regional integration, as of structural problems limiting the ability of a region's member countries to participate in the international trade network. ${ }^{3}$

Our underlying assumption is that, other things being equal, international production linkages increase the intensity of trade, especially in intermediate goods, so that high RTP indices can be seen also as an indirect sign of the presence of IPNs. Of course, other proximity factors, including geography, culture, migrations and preferential trade agreements, can generate the same result and no causal relationship can be established on the basis of our descriptive analysis. Our only ambition is to measure correctly the intensity of bilateral trade, to identify country groupings in which we can expect to see traces of IPNs. The structure of these preferences will then be studied with the help of social network analysis in Section 5.

With reference to total trade, Figs. 1 and 2 display regional introversion indices respectively for electronics and textiles. In the first case regionalization increases for some areas and declines for others. The decline in regional introversion is limited to American and Asian regions (with the exception of Central and Southern Asia), but their importance in world trade makes so that even the weighted average across all regions slightly falls (from 0.75 to 0.74 ).

On the contrary, in textiles we observe a wide-spread downward trend in regionalization: only two regions (non-EU Europe and North Africa) show an increase in trade introversion, starting from relatively low levels (the world weighted average of regional introversion falls from 0.67 to 0.60 ). North Africa, in particular, is the only region characterized by a negative intra-regional trade preference, possibly due, on one hand, to political conflicts and persistent high trade barriers within the region, and on the other hand on the strength of preferential linkages with the European Union, resulting also from Euro-Mediterranean Association Agreements.

In 2014, East Asia, the European Union and NAFTA accounted for 90 per cent of world trade (exports plus imports) in electronics and 75 per cent in textiles. ${ }^{4}$ Given this concentration, we will now limit our analysis to these three regions, considering the distribution of

\footnotetext{
2 Similar results can be obtained with a more sophisticated index of homophily, proposed by Newman (2003), which is in the range between 0.3 for consumption goods and 0.4 for intermediate goods, but shows a slight fall in both categories between 2007 and 2014.

3 For a formal presentation of RTP indices, see Annex 2.

${ }^{4}$ Between 2007 and 2014, East Asia's share of world trade rose from 47 to 53 per cent in electronics and from 31 to 35 per cent in textiles, whereas the shares of NAFTA and particularly of the EU dropped in both industries.
} 


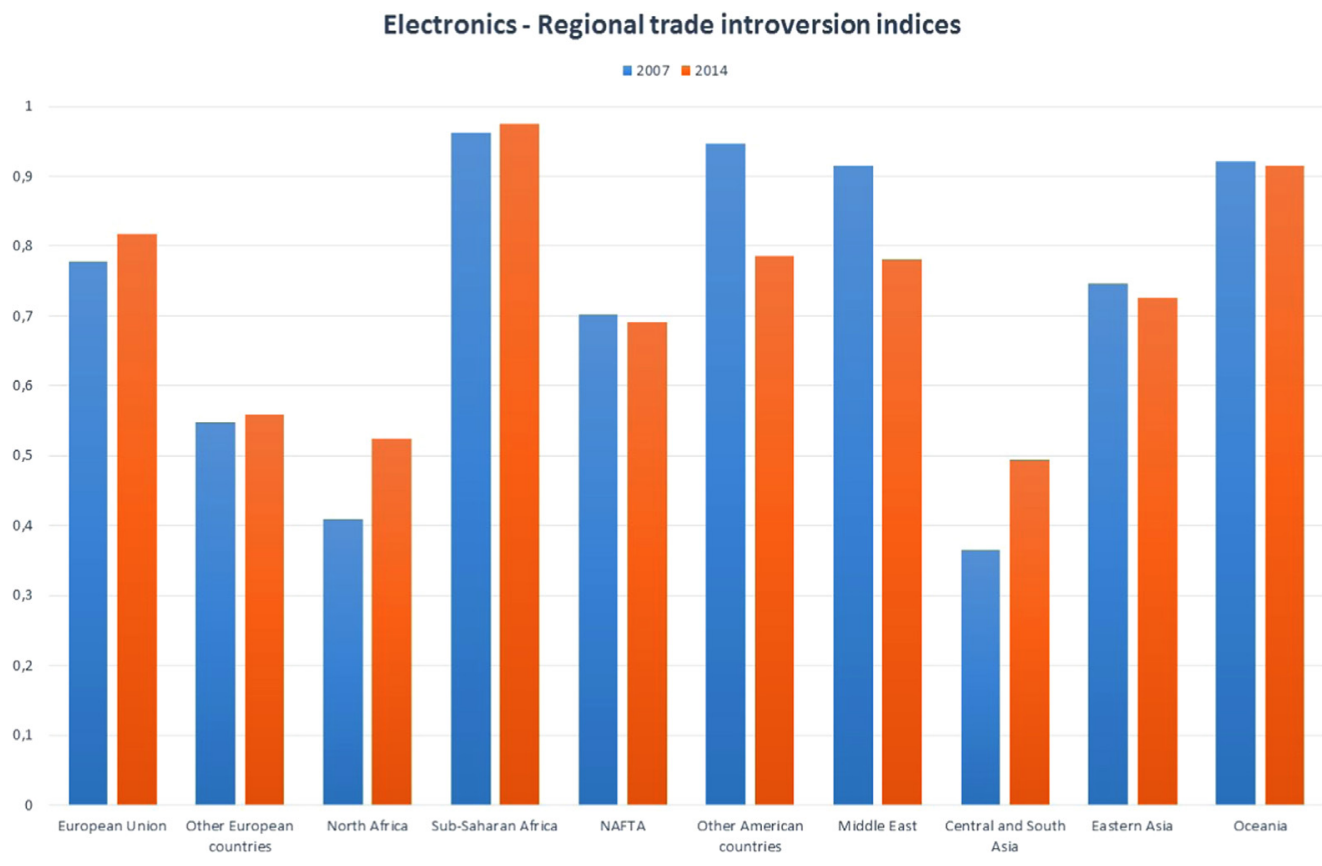

Fig. 1. Electronics - Regional trade introversion indices (Source: our elaboration on COMTRADE database).

RTP indices by production stage and by partner region in each industry.

As shown in Table 2, regional trade introversion in electronics is relatively high in all the three regions, but shows different trends along the production chains. In intermediate goods, an upward trend is visible between 2007 and 2014 in all the three regions, confirming the idea that the manufacturing core of the industry has become more regionalized. On the other hand, introversion indices have fallen in East Asia and in NAFTA for consumption goods.

The picture of the textile industry is quite different. Regional trade introversion is higher for intermediates than for consumption goods in the EU and NAFTA, but the opposite occurs in East Asia. The downward trend in regionalization is visible everywhere, with the exception of intermediates in the EU, and is particularly strong in East Asia, reflecting mostly the increasing global reach of Chinese products.

A better understanding of trade geography can be drawn by considering the distribution of RTP indices by partner region, distinguishing between export and import preferences. Figs. 3-5 refer to the electronic industry and Figs. 6-8 to the textile industry.

In the case of East Asia, Fig. 3 suggests clearly the idea that the manufacturing basis of the electronics production network is limited to the region. Trade preferences for intermediate goods are concentrated on intra-regional flows, whereas for consumer goods the distribution of preferences is more dispersed, particularly for exports. Overall, these indices seem to confirm the central role played by this region in the international electronics industry, with a strong core of intra-regional trade in intermediate goods, generating substantial extra-regional flows of consumption goods, particularly towards the Americas.

The case of the European Union (Fig. 4) is less clear-cut than that of East Asia. In addition to a strong regional introversion, the EU shows high RTP indices towards neighbouring regions (Other European countries and North Africa, particularly for intermediates). However, unlike in East Asia, the structure of its revealed trade preferences is more concentrated for consumption than for intermediate goods. In the latter group, its network of preferential import suppliers includes also Central and South Asia, and its export preferences extend also to Middle East and Sub-Saharan Africa. Overall, the geographic scope of EU's trade preferences goes beyond the boundaries of the region, but is anyway influenced by distance and does not extend to the largest extra-regional markets.

Similar features characterize the geography of NAFTA's trade (Fig. 5). Regional introversion is high, and could be traced back not only to the preferences envisaged by the free trade agreement, but also to the development of cross-border production linkages among firms. However, revealed trade preferences emerge also towards other American countries, particularly for imports of intermediates and exports of consumption goods. Moreover, unlike the EU, NAFTA shows strong import linkages also with Asia in consumption goods.

In the case of the textile industry, the geography of trade looks more diversified. Fig. 6 refers to East Asia and shows that revealed import preferences for intermediates go beyond the region, extending to other suppliers of raw materials (Oceania and Sub-Saharan Africa), whereas export preferences are relatively high also in the Middle East and in Central and Southern Asia. In consumption goods the pattern of trade is simpler: revealed import preferences are exclusively intra-regional, whereas export preferences cover almost every region, excluding Europe.

In the case of the European Union (Fig. 7) the geography of trade is similar to what already seen for electronics. For both intermediate and consumption goods revealed trade preferences are not exclusively intra-regional, but extend only to a couple of neighbouring regions (Other European countries and Northern Africa). The only exception is a moderate degree of import preference for 


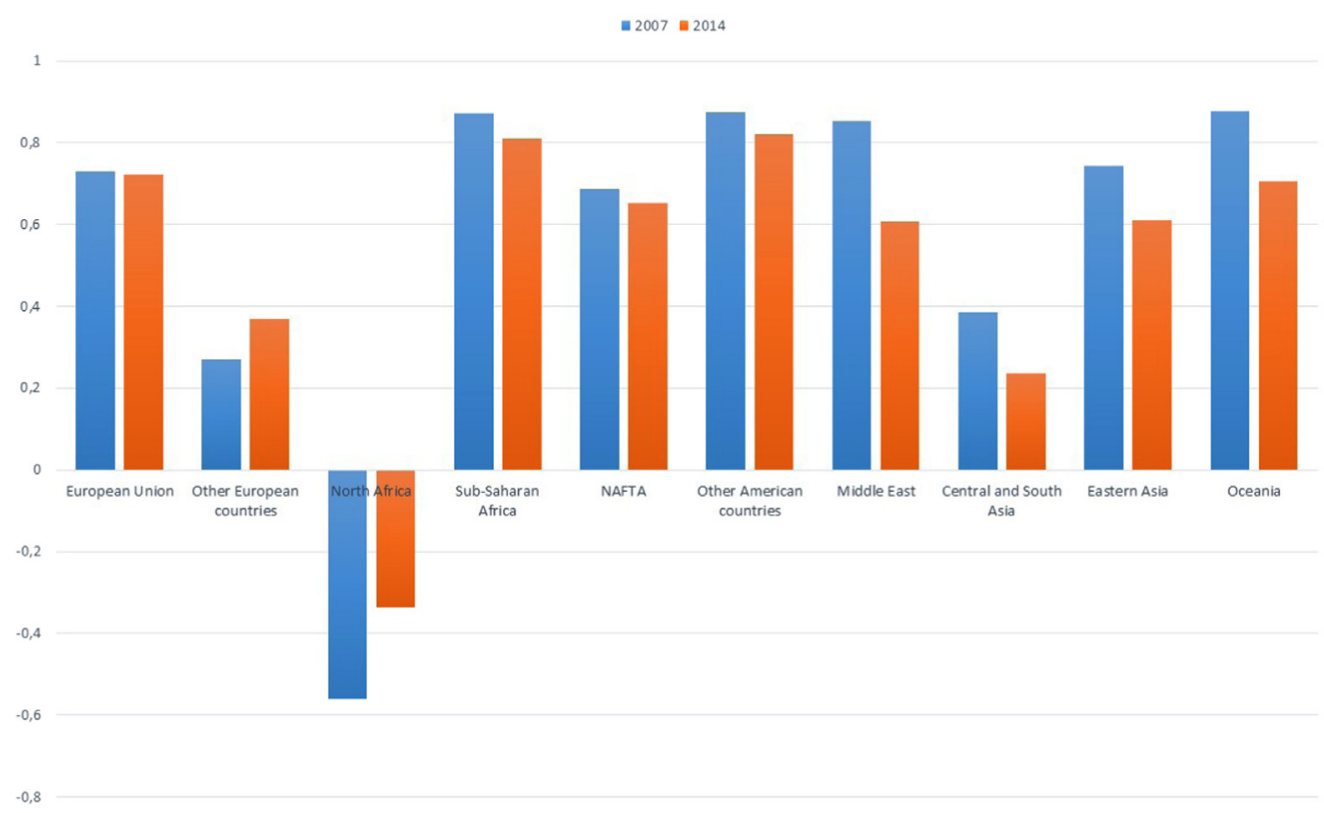

Fig. 2. Textiles - Regional trade introversion indices (Source: our elaboration on COMTRADE database).

Table 2

Regional trade introversion indices (Source: our elaboration on COMTRADE database).

\begin{tabular}{llll}
\hline Regional trade introversion indices & & & \multicolumn{2}{c}{ Consumption goods } \\
\hline & Intermediate goods & 2014 & 2007 \\
\cline { 2 - 4 } & 2007 & & 0.80 \\
\hline Electronics & & 0.81 & 0.85 \\
$\quad$ Eastern Asia & 0.79 & 0.85 & 0.87 \\
European Union & 0.81 & 0.76 & 0.75 \\
NAFTA & 0.73 & & 0.84 \\
Textiles & & 0.57 & 0.71 \\
Eastern Asia & 0.75 & 0.83 & 0.80 \\
European Union & 0.83 & 0.80 & 0.72 \\
NAFTA & 0.83 & & 0.79 \\
\hline
\end{tabular}

consumption goods from Central and Southern Asia.

NAFTA's regional trade introversion is only slightly higher for intermediate than for consumption goods (Fig. 8). In the former group, revealed export preferences extend also to the rest of America, whereas import preferences are significant from the Middle East, possibly reflecting also the effects of bilateral free trade agreements linking Israel and Jordan with Canada and the United States. In consumption goods, revealed import preferences show a higher degree of geographic diversification, and are particularly strong from the rest of America.

In conclusion, the structure of revealed trade preferences in the three largest regions supports the idea that the degree of trade regionalization is still strong, notwithstanding the progress achieved by globalization in the two decades before the great crisis. On one hand, this might reflect the trade creation and diversion effects of the preferences embedded in regional integration agreements. On the other, this is also the result of a process driven by the international production strategies of enterprises, leading to the development of regional networks, particularly for intermediates. Yet, the extra-regional trade preferences revealed by the data suggest the possibility that the extension of some networks goes beyond regional boundaries.

Performing the analysis of revealed trade preferences for single countries can allow to better understand their place in the international division of labour.

One simple and interesting information is given by the total number of positive RTP indices, which can be seen as measuring the 'extensive margin' of revealed trade preferences, or the degree of geographic diversification of a country's trade pattern. Table 3 refers to the five largest trading countries in each sector, ${ }^{5}$ and shows remarkable differences in the number of their preferential linkages. The

\footnotetext{
5 The ranking is based on the total value of trade (exports plus imports) in 2014.
} 

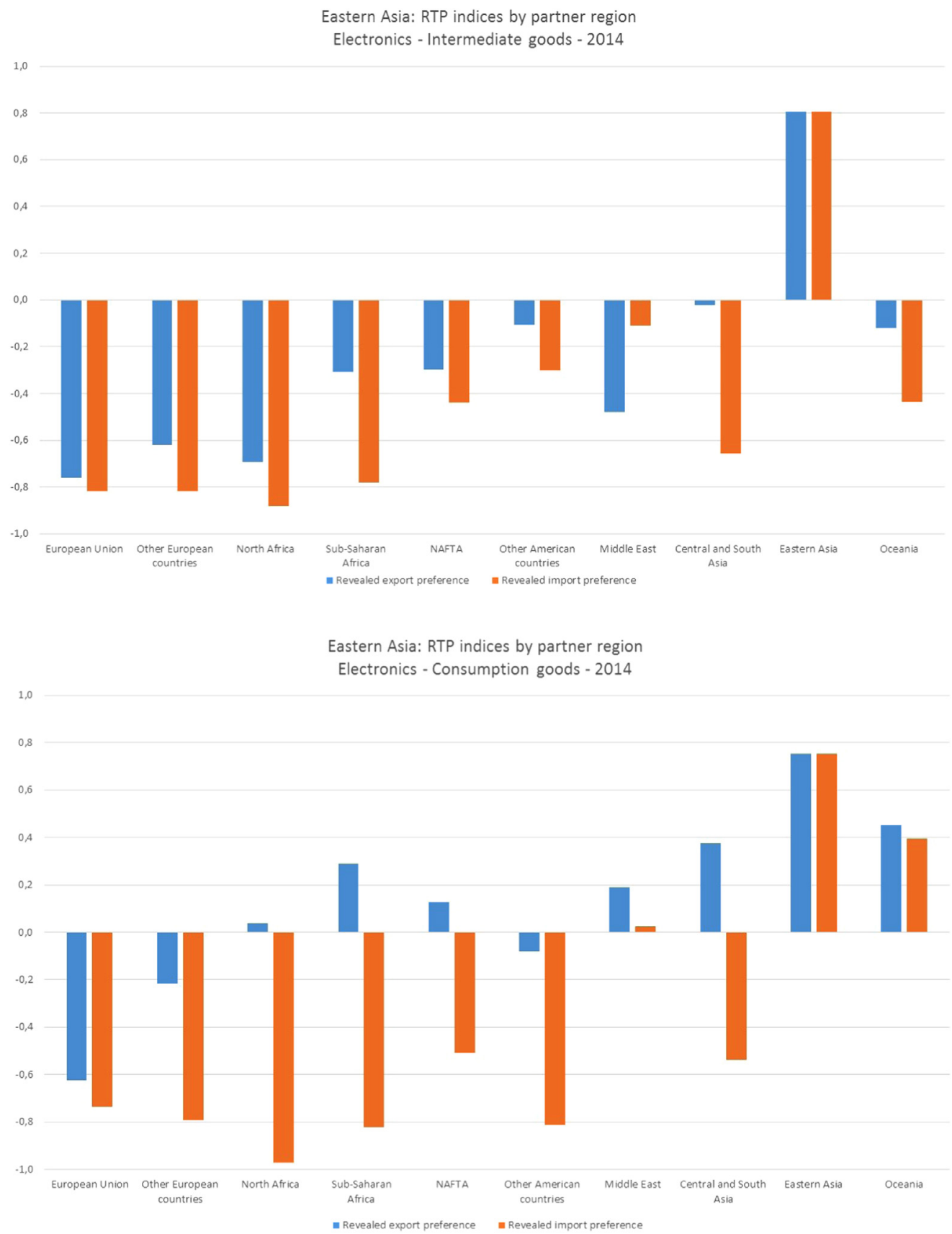

Fig. 3. Eastern Asia - RTP indices by partner region - Electronics - 2014 (Source: our elaboration on COMTRADE database).

analysis is limited to total trade, as the disaggregation between intermediate and consumption goods does not show significant differences.

In electronics, it is interesting to note that the number of preferential partners is systematically larger for exports than for imports, which suggests the idea that import suppliers are concentrated in a relatively limited number of countries, specialised in the upstream segments of international production networks. This is true in particular for China and Hong Kong, whose trade preferences are much less diversified for imports than for exports. Taiwan stands out for a very low number of revealed trade preferences, concentrated in Asia, on both sides. ${ }^{6}$

During the crisis, the extensive margin of import preferences has dropped in all the top five traders, except Hong Kong. The number

\footnotetext{
${ }^{6}$ The low number of Taiwan's preferential trade partners could be partly due to the unsettled disputes about the political status of this territory, reflected by the fact that it is not included in the trade data published by several reporting countries.
} 


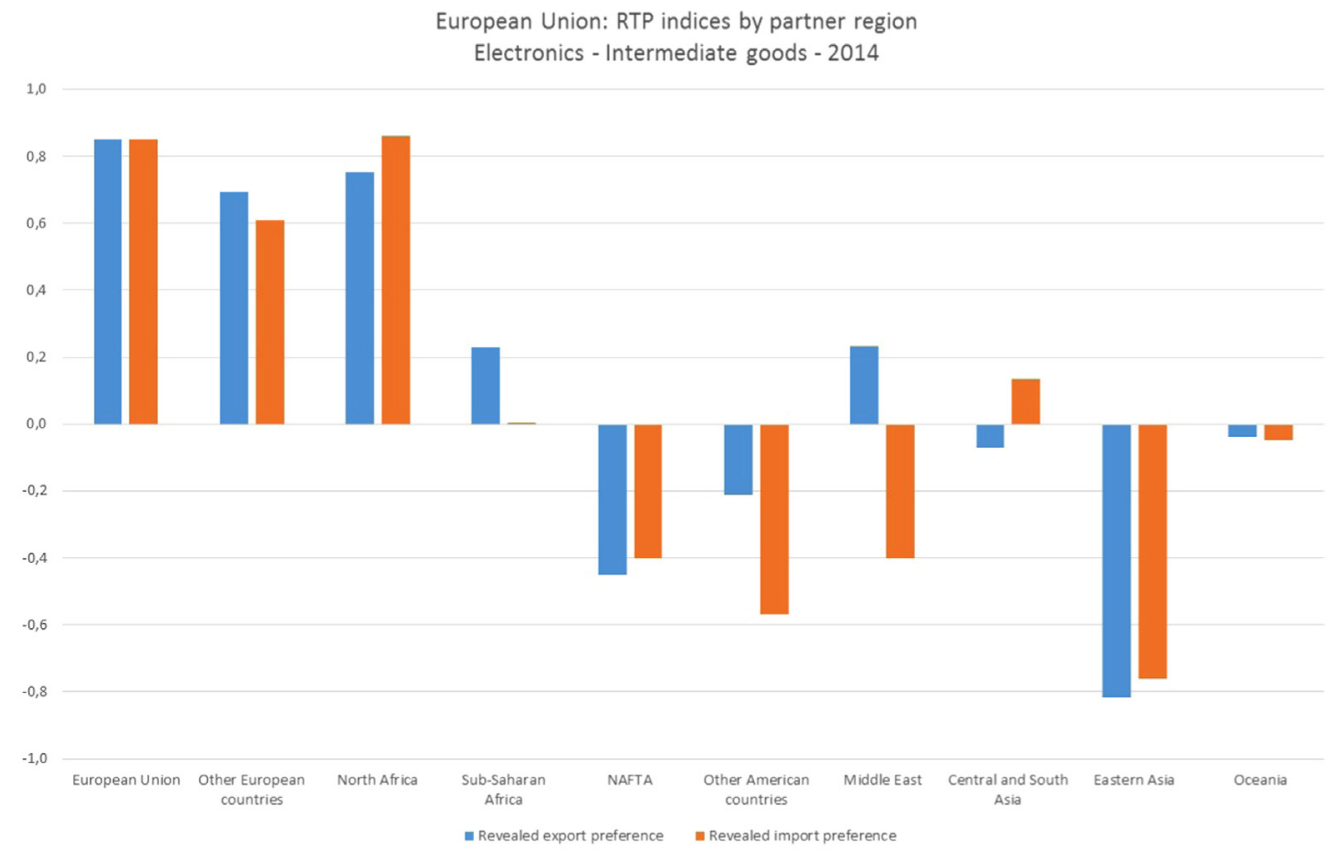

European Union: RTP indices by partner region

Electronics - Consumption goods - 2014

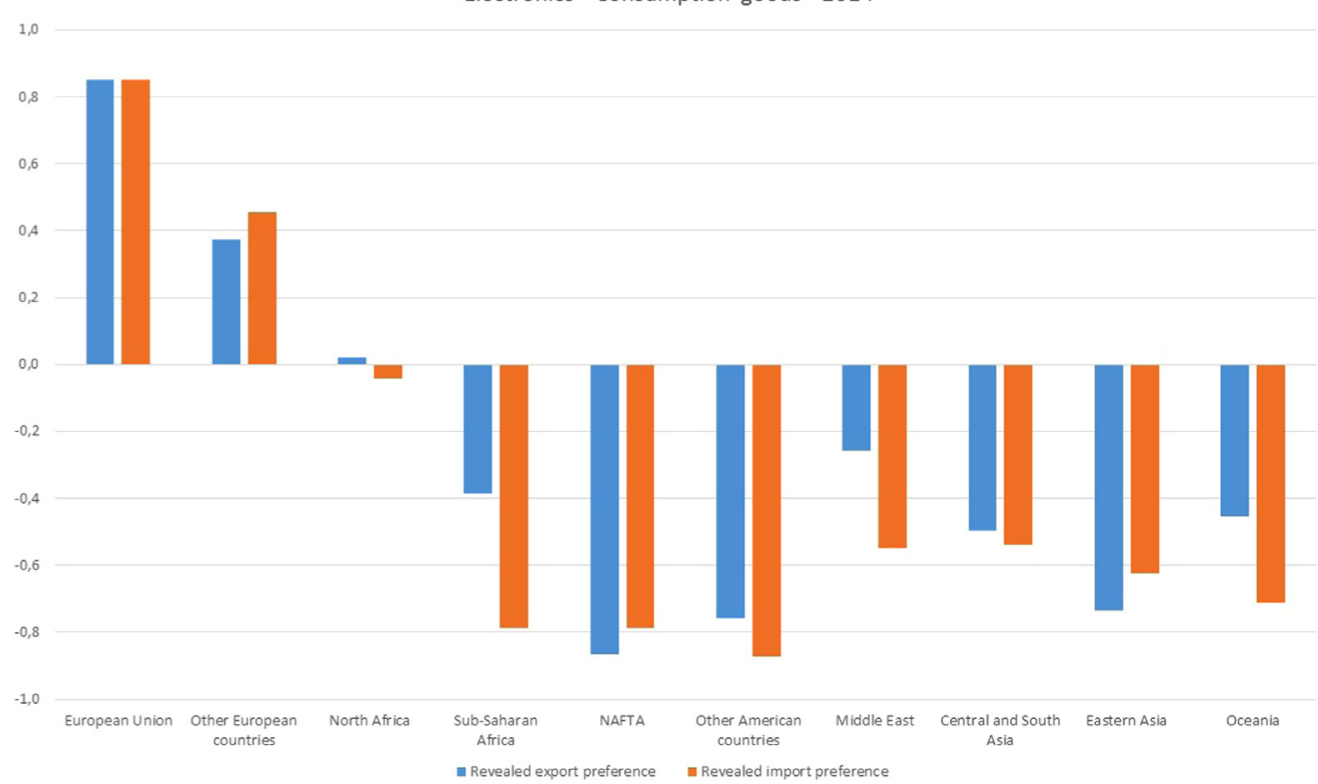

Fig. 4. European Union - RTP indices by partner region - Electronics - 2014 (Source: our elaboration on COMTRADE database).

of revealed export preferences has increased remarkably in China and Hong Kong.

The five top traders of the textile industry in 2014 were China, the United States, Germany, Italy and the United Kingdom. The distribution of their revealed trade preferences is less diversified than in the electronics industry.

China stands out for a larger and increasing number of revealed preferences, particularly in exports. In the other four countries, the crisis has not affected substantially the extensive margin of RTPs. On the import side, the number of UK's preferential partners has dropped during the crisis, but remains higher than in the other main EU traders.

\section{Looking at the structure of international production through the lens of network analysis}

In Section 4, trade regionalization was measured with reference to ten exogenously defined regional groupings, which were used to 


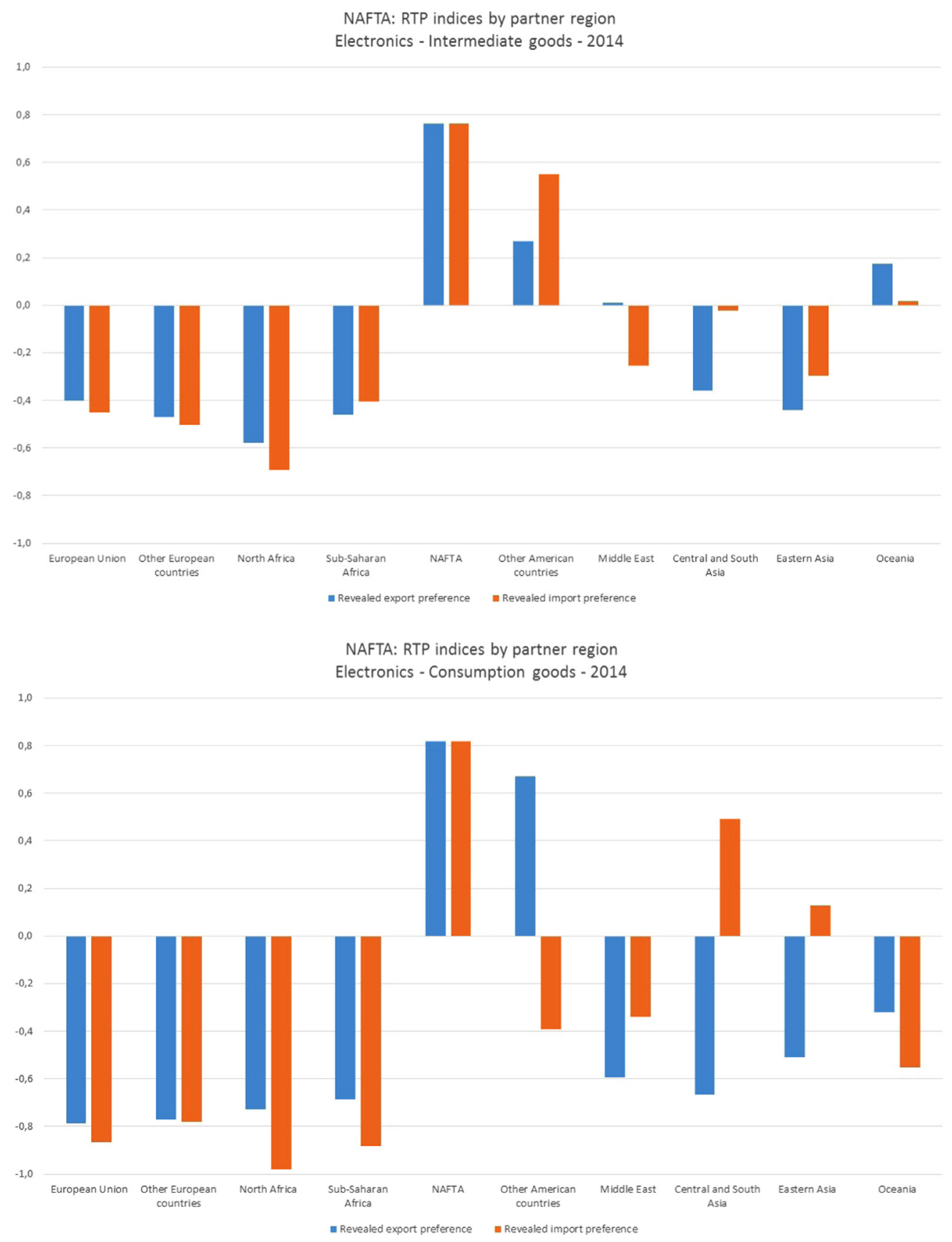

Fig. 5. NAFTA - RTP indices by partner region - Electronics - 2014 (Source: our elaboration on COMTRADE database).

organize our descriptive analysis. However, revealed trade preferences can of course emerge also among countries belonging to different regions, and IPNs can play an important role in establishing and sustaining these linkages. Therefore, it can be useful to analyse the structure of bilateral preferences in the world trade network independently of any exogenous regional classification.

This is what we do in this section, where we apply some statistical tools developed in the context of social network analysis to our bilateral RTP indices. More precisely, we build the network created only by preferential trade linkages in each industry, that is a binary directed network, where a link between two nodes exist only if the revealed trade preference index computed for the country pair $(\mathrm{i}, \mathrm{j})$ is positive.

The resulting networks for intermediate and for consumption goods in the two industries in 2014 are pictured in Figs. 9-12, which have been obtained with the network visualization software Gephi@ (see Annex 3).

The figures highlight that regionalization of trade preferences emerges endogenously from the data, as the algorithm building the 


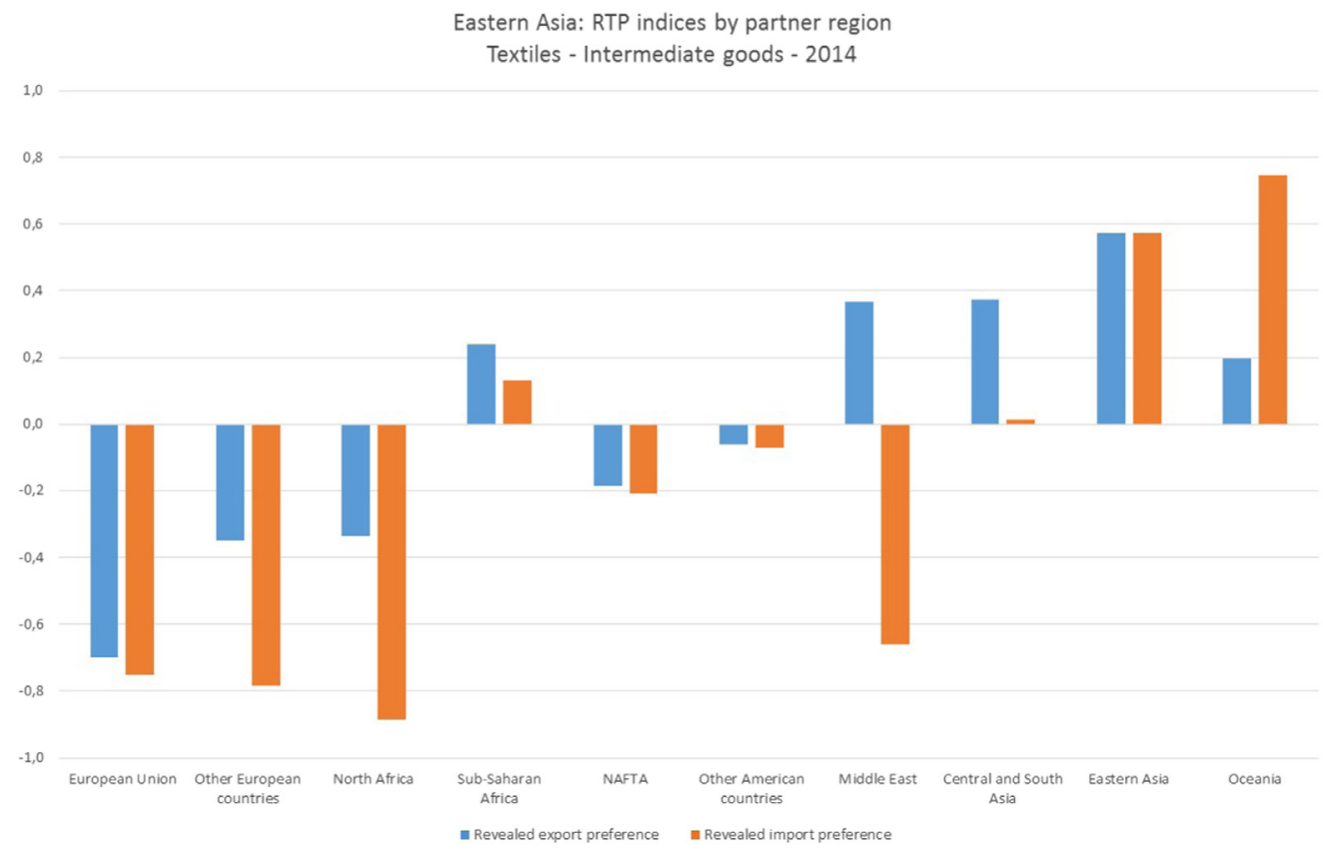

Eastern Asia: RTP indices by partner region

Textiles - Consumption goods - 2014

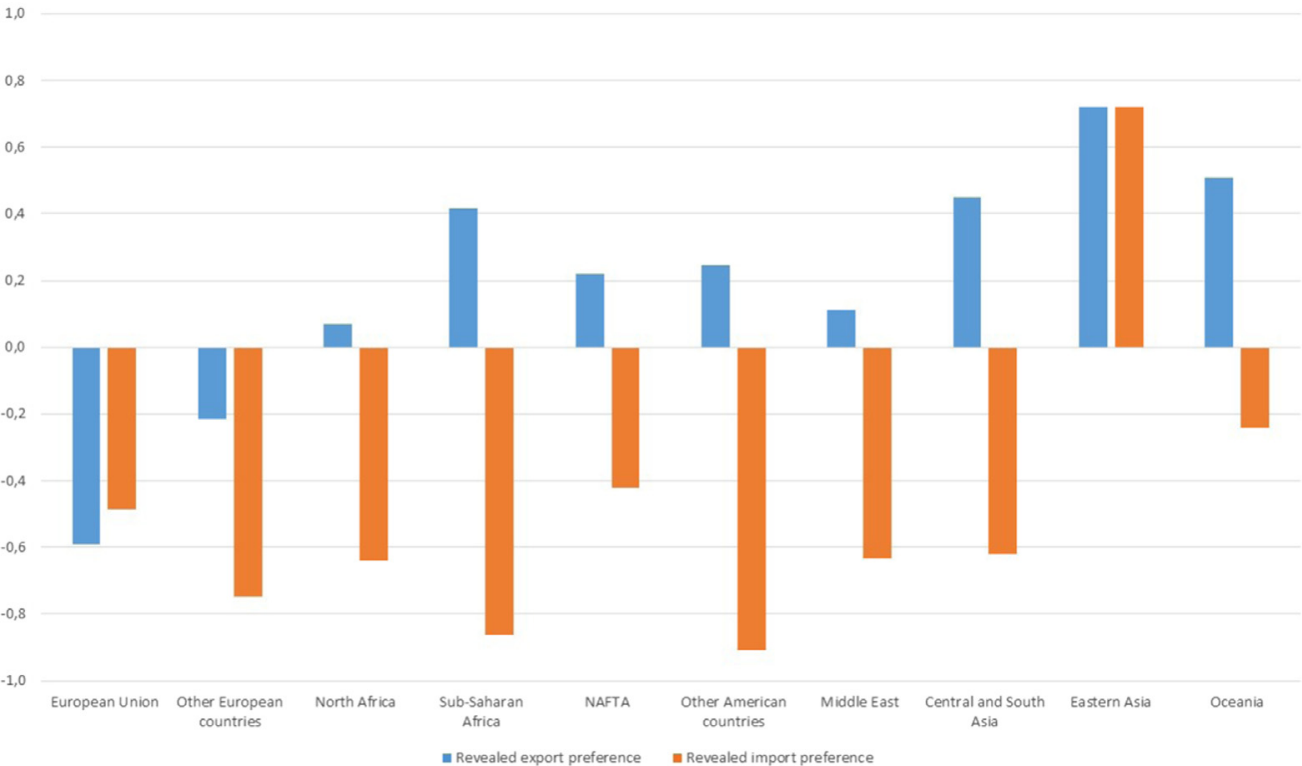

Fig. 6. Eastern Asia - RTP indices by partner region - Textiles - 2014 (Source: our elaboration on COMTRADE database).

graphs puts close to each other countries that are more connected, and continental groups clearly emerge, even if the geographic position of each country does not affect the algorithm's behaviour. ${ }^{7}$ The clusters of countries do not overlap exactly with our ten exogenous regions, but nearby regions appear often next to each other.

The graphical representation also confirms the non-random and non-uniform distribution of revealed trade preferences. The size of the node representing each country is proportional to the sum of incoming links, and in some regions, the structure of preferences

\footnotetext{
${ }^{7}$ The algorithm requires the choice of some parameters to draw the resulting pictures. We tested different parameters' sets, but the resulting overall regionalization pattern observed in the figures is not significantly modified.
} 


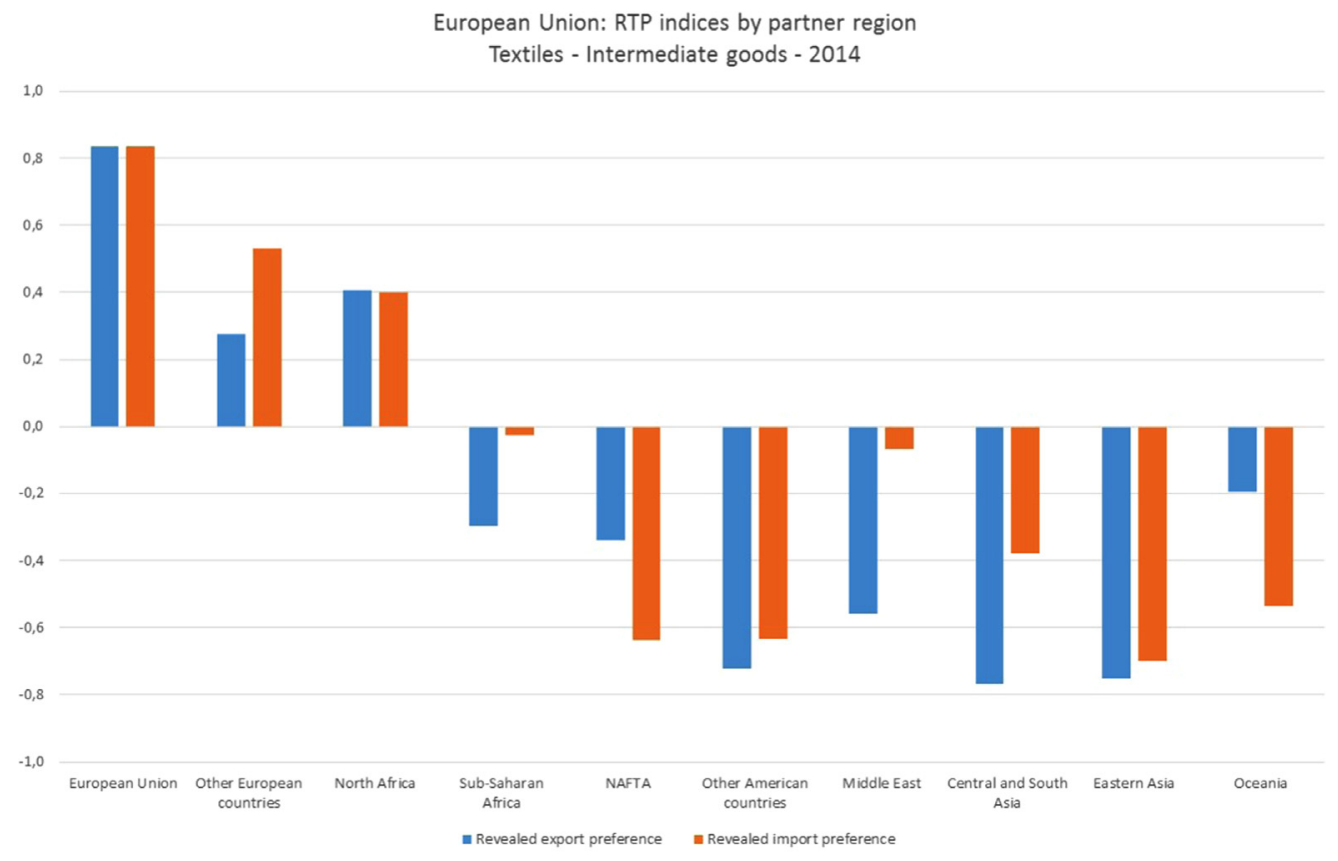

European Union: RTP indices by partner region

Textiles - Consumption goods - 2014

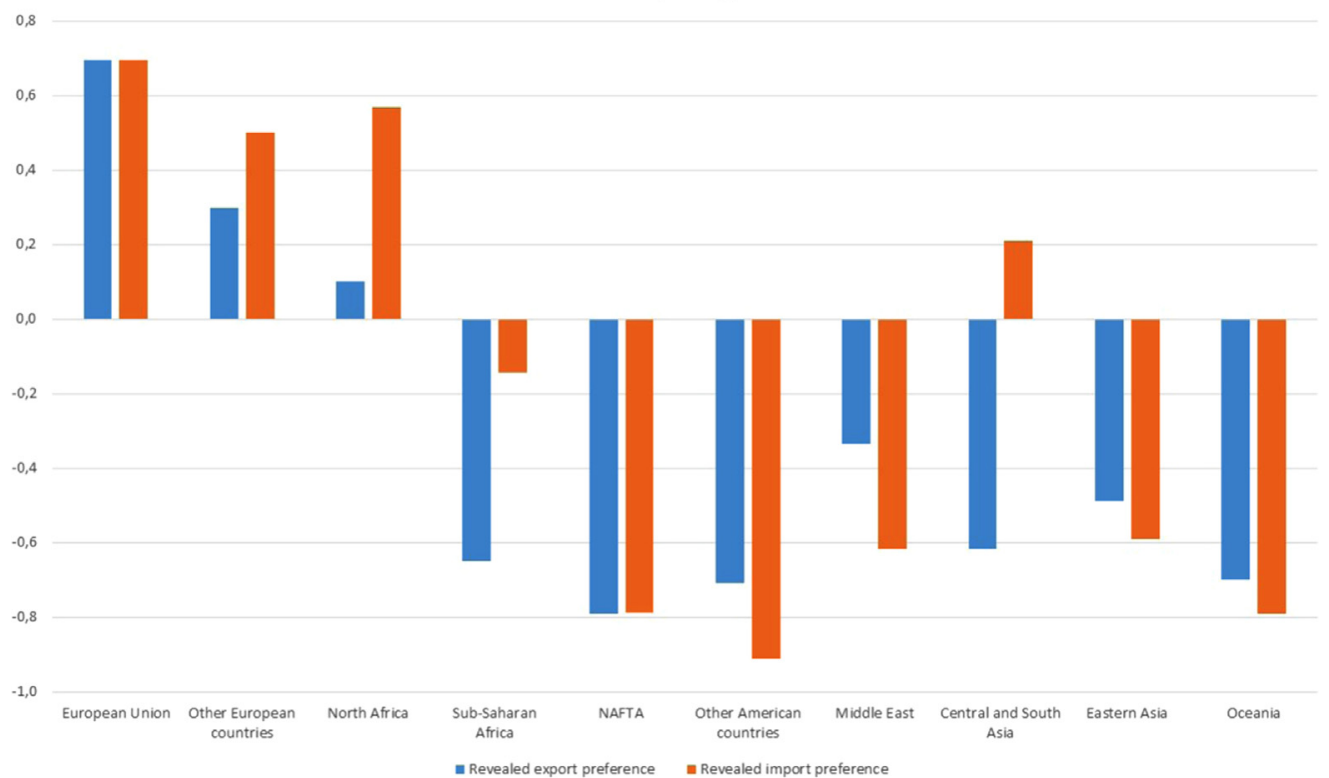

Fig. 7. European Union - RTP indices by partner region - Textiles - 2014 (Source: our elaboration on COMTRADE database).

appears built around some specific "large" central nodes. For example, this is the case of preferential trade in intermediate electronic goods in East Asia, assigning a central role to South Korea. Instead, East Asia, and in particular China and Singapore, play the role of connecting America and Europe in consumers electronics. Italy is central for trade in intermediates and in consumption goods in the textile and apparel industry in Europe, and in the case of intermediates, it also bonds the EU towards other non-EU nearby countries. China is close and reveals strong preferential trade connections to North America in the case of apparel goods, while America appears more regionalized with respect to trade in intermediates in this industry.

To better assess the characteristics of the structures pictured in Figs. 9-12, it is useful to examine the topological indices of these networks. The main indicators for each network are presented in Tables 4, 5 (for a detailed description of these indices, see Annex 4), starting with density, which measures the number of existing links as a share of total potential links. In our networks, a higher number of 


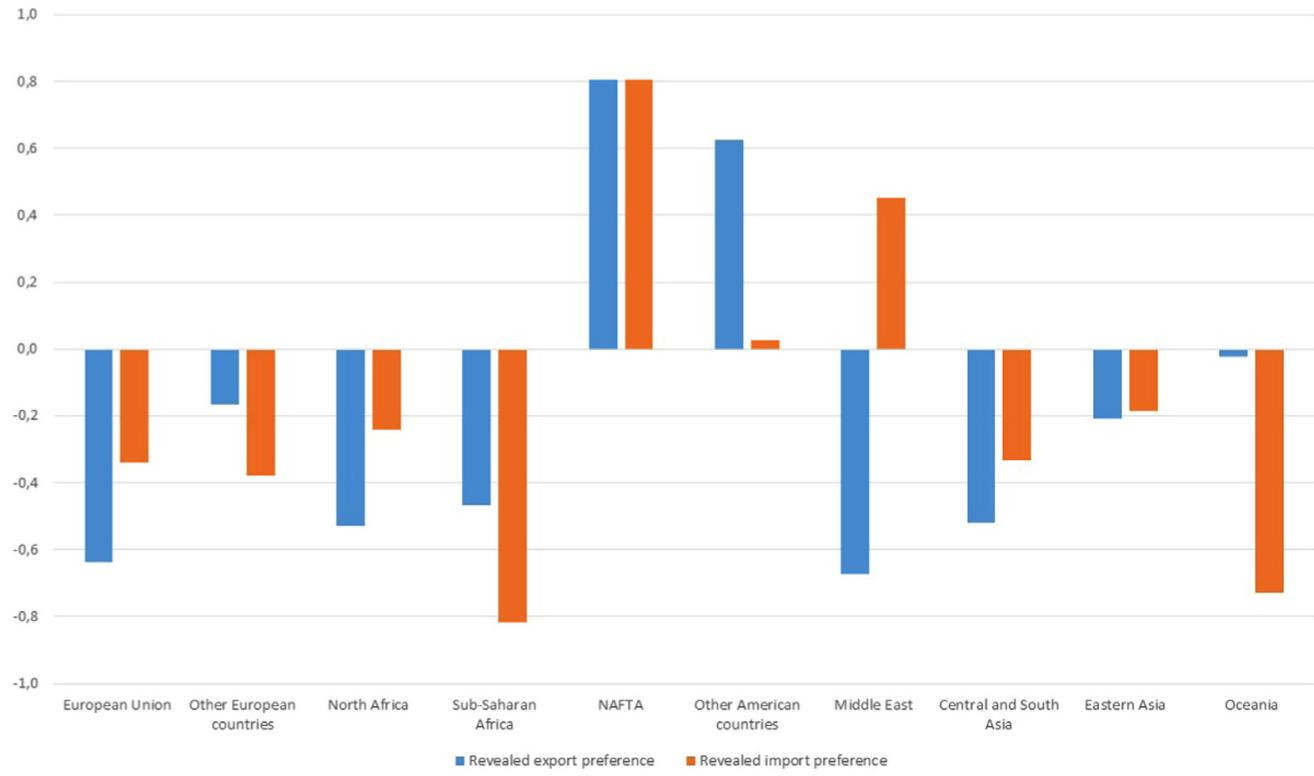

NAFTA: RTP indices by partner region

Textiles - Consumption goods - 2014

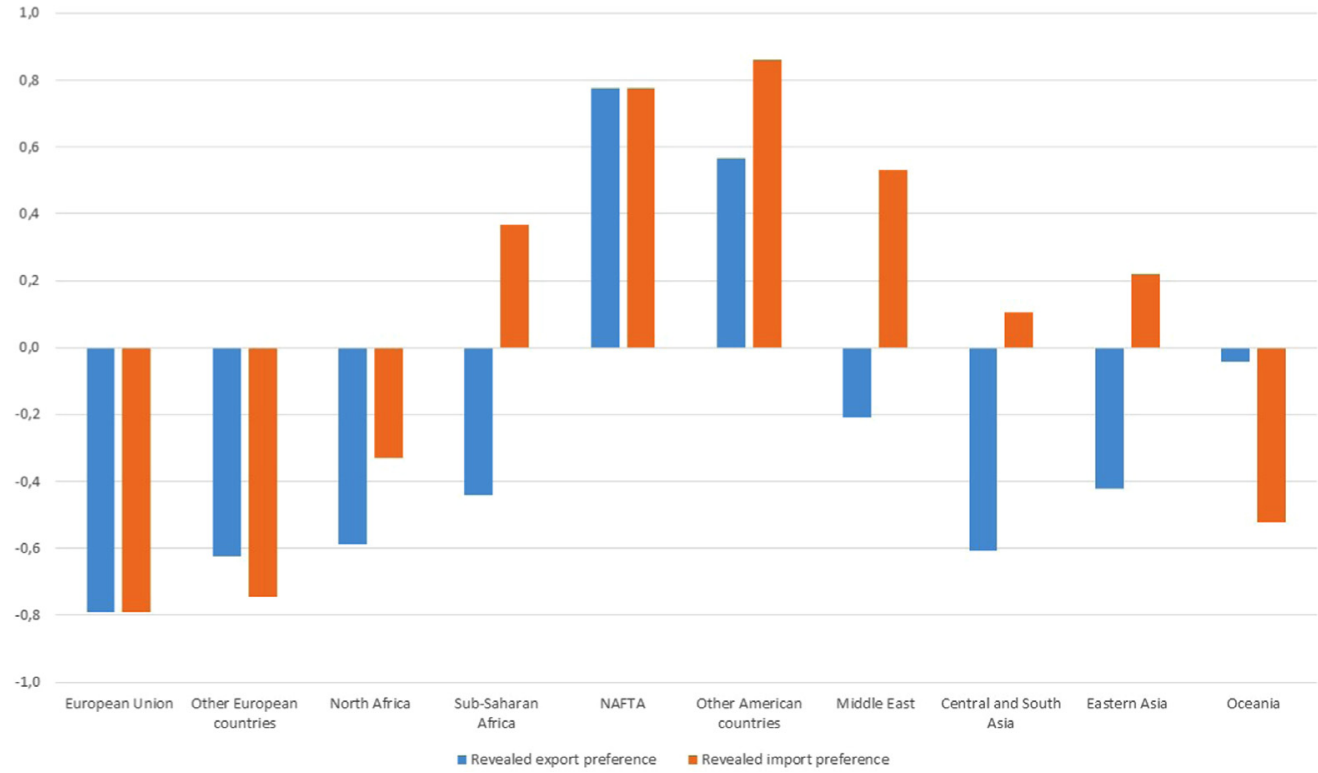

Fig. 8. NAFTA - RTP indices by partner region - Textiles - 2014 (Source: our elaboration on COMTRADE database).

revealed preferential partners means more links, and therefore a higher density, regardless of the intensity of preferences. Actually, a very strong preference toward very few partners would imply a very scattered network with low density. On the other hand, with no preferences at all and a uniform distribution of trade flows across countries, the network of preferences would be empty and the density measure would be zero. By definition, at the world level we can never have a complete network in terms of preferential linkages, as preferences are selective and there cannot be a preference for all other countries. Indeed, we can observe that the density of preferential trade networks is much lower than the density of the networks built using all trade links at the industry level (see De Benedictis and Tajoli, 2010). At the world level, the extent of preferentiality seems stable over our observation period, and low in both industries, even if slightly higher in electronics.

At the regional level, the network of preferences can be complete if all members of the region reveal a preference for all the other 
Number of preferential trade partners (Source: our elaboration on COMTRADE database).

\begin{tabular}{|c|c|c|c|c|c|c|c|c|c|}
\hline \multicolumn{10}{|c|}{ Number of preferential trade partners } \\
\hline & \multicolumn{4}{|c|}{ Electronics } & & \multicolumn{4}{|c|}{ Textiles } \\
\hline & \multicolumn{2}{|c|}{$\begin{array}{l}\text { Revealed import } \\
\text { preferences }\end{array}$} & \multicolumn{2}{|c|}{$\begin{array}{l}\text { Revealed export } \\
\text { preferences }\end{array}$} & & \multicolumn{2}{|c|}{$\begin{array}{l}\text { Revealed import } \\
\text { preferences }\end{array}$} & \multicolumn{2}{|c|}{$\begin{array}{l}\text { Revealed export } \\
\text { preferences }\end{array}$} \\
\hline & 2007 & 2014 & 2007 & 2014 & & 2007 & 2014 & 2007 & 2014 \\
\hline China & 20 & 16 & 46 & 71 & China & 38 & 50 & 64 & 81 \\
\hline United States & 33 & 31 & 50 & 51 & United States & 45 & 39 & 50 & 55 \\
\hline Germany & 45 & 36 & 62 & 50 & Germany & 45 & 42 & 41 & 41 \\
\hline Hong Kong & 12 & 22 & 56 & 72 & Italy & 48 & 51 & 42 & 46 \\
\hline Taiwan & 9 & 7 & 11 & 7 & United Kingdom & 36 & 41 & 64 & 57 \\
\hline
\end{tabular}

members for importing and exporting a given class of goods. Unsurprisingly, the density indicator is much higher within specific country groups than at the world level, confirming the impression conveyed by the visual representation of the networks and the role of geography in determining trade preferences. However, other factors are at work, as shown by the EU and NAFTA, whose intra-regional preference density is nearly twice as high as in East Asia in the case of electronics. Moreover, density is higher for the subset of intermediate goods than for consumption goods in electronics, with the relevant exception of East Asia, while in textiles this is not always the case. In other words, intra-regional preferentiality appears to be higher when trade is driven by production links than when final goods are sold, especially in an advanced sector. These results seem only in part in line with what shown by revealed trade preferences (see Table 2), since density computed on a binary network does not take into account trade values but only the number of bilateral preferences. Therefore, even if the intensity of intra-regional trade in East Asia is very high in terms of values, this result might be driven by a subset of countries in the area, but it does not imply that all countries in the region reveal a preference towards each other.

Density appears stable over time when comparing the indicator between 2007 and 2014: in spite of the sharp fluctuations occurred to the value of world trade in this period, the amount of preferential trade links displays a remarkable resilience to the global crisis. Density of regional preferences in general shows a small decline in less developed regions, possibly because of more integration of those countries with the rest of the world.

More interesting are the other topological indicators that add information on links of higher order. Like the previous ones, they cannot be directly compared to the set of results of Section 3, not only because they are built on a binary network, but also because they consider each country's position beyond its bilateral preferential links, looking also at the position of its partners. Clustering is the simplest of such indicators. High clustering indicates more symmetric preferences within a group, as it indicates that the preferred partners of a given country also prefer each other. The clustering coefficient is higher at the regional level than at the world level, especially for the $\mathrm{EU},{ }^{8}$ also confirming that regionalization of trade preferences is still strong. In electronics, and to a smaller extent in textiles, clustering also shows that regional symmetric preferences are generally stronger in intermediate than in consumption goods. This seems to confirm the existence of regional production networks connecting countries through the symmetric exchange of intermediate goods. In advanced regions, clustering in electronic intermediates shows a moderate increase in the recent past, which seems to indicate a more intense reciprocal degree of preferentiality among such countries. Instead, the index falls over time in the case of African and Asian countries.

The next set of network indicators measures assortativity, defined as the likelihood that similar or dissimilar countries in terms of preferential connections are themselves connected. The overwhelming negative sign of this indicator suggests that weakly preferred countries tend to prefer strongly connected and preferred countries. This is a sign of asymmetry in the networks, hinting to the likely presence of more and less central countries, as already suggested by the visual inspection of the networks. In the electronic industry, especially for intermediates and for Asian countries, disassortativity is increasing over time. This change, together with the reduction in clustering, might hint to a re-organization of the production networks in those regions. Disassortativity is generally weaker for textiles and apparel, showing more evenly distributed preferences in this sector.

Finally, the last set of network indicators further examines this asymmetry by measuring the centralization of each industry and each region. We chose the simplest centrality indicator, degree centrality, based on the number of links (revealed preferences in our case) of each node, and differentiating between in-coming and out-going preferential links. If a network is highly centralized, the distribution of preferences is very uneven, with the limit case of a star-like structure, with peripheral countries preferring a single central country, which is instead directly connected to all the other countries. Looking at this indicator, we find that at the world level the extent of centralization is not very high, and generally below 0.5 (the value for a perfect star would be 1 ). Furthermore, centralization at the world level has declined in electronics, especially for intermediate goods, showing a larger number of countries becoming preferred pro-duction locations for these goods.

In electronics, centralization in terms of out-degree is much higher than in terms of in-degree, as production and exports are concentrated in a relatively small number of countries, while the number of relevant and preferred markets of destination is relatively high. Inward centralization is in fact especially low for consumption goods, while centralization is generally higher for intermediates, confirming the uneven structure of trade along IPNs. In the less complex IPN of textiles and apparel, centralization is not very high even for

\footnotetext{
8 In the case of NAFTA this is only the trivial result of having only three member countries.
} 


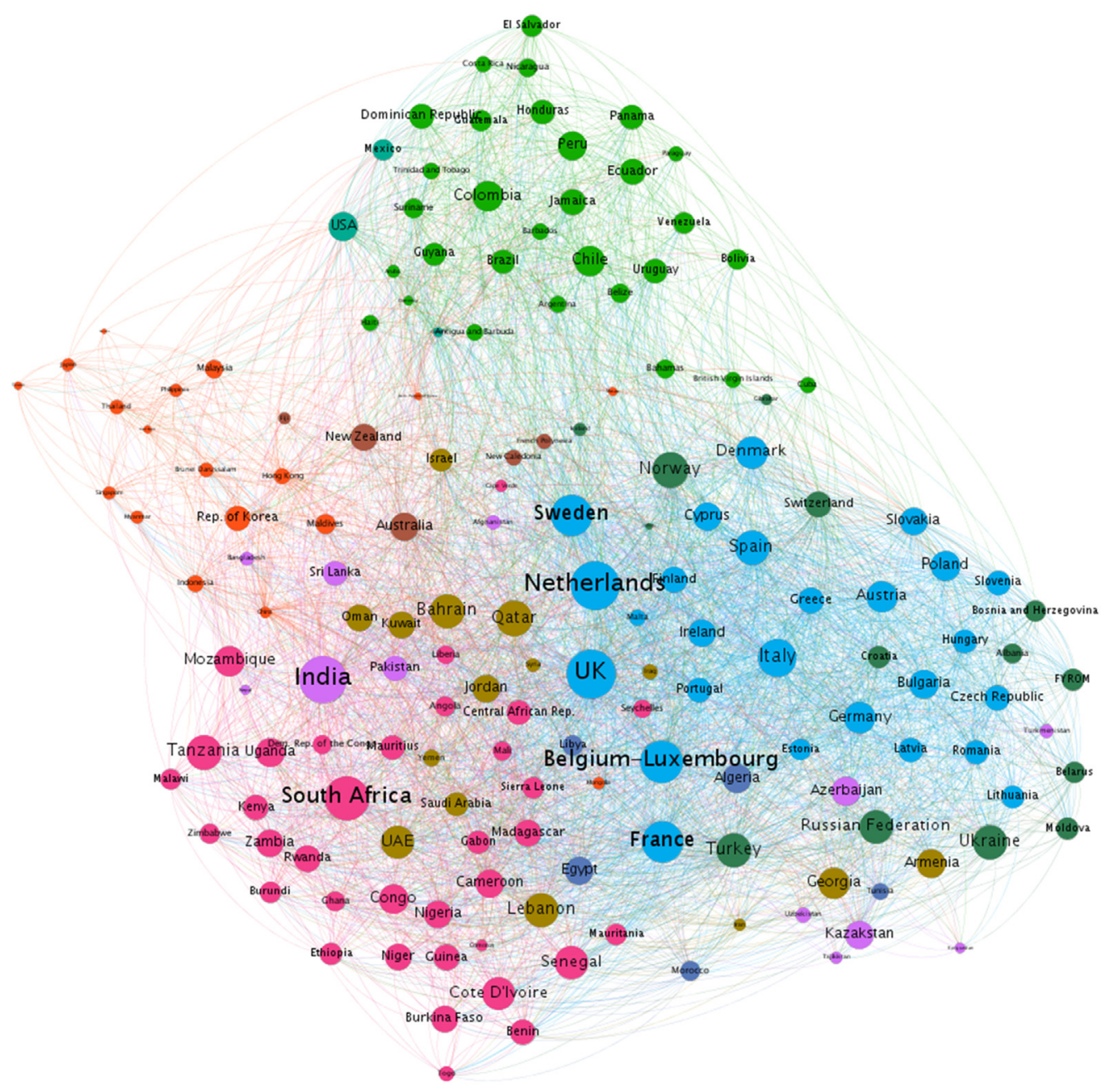

Fig. 9. Network of preferential trade in Electronics in 2014 - Intermediate goods (Source: our elaboration on COMTRADE database).

intermediate goods. At the world level, in electronics we observe a decrease in centralization in the past years, while in textiles centralization is slightly increasing over time, displaying a tendency to create some production hubs. Instead, within specific regions, centralization seems to increase in electronics, and no clear pattern is observed for textiles.

The most central country is different when considering total trade or trade in intermediates only, and when considering inward or outward trade flows in different industries. The most centrally preferred destination for final consumer electronic goods in 2007 was France, while Italy had the highest outward centrality. Instead, for intermediate goods UK and Sweden displayed the highest inward and outward centrality, respectively, in terms of preferences in 2007. Confirming the shift that occurred in trade patterns in this industry, the most centrally preferred countries in 2014 became South Africa and China in terms of in-degree and out-degree centrality respectively, considering consumer goods. In terms of intermediates, the situation remained more stable, with the Netherlands and Sweden as the most central nodes. In textiles and apparel, the centrally preferred countries are different than in electronics, with the US losing the highest centrality as preferred market of consumer goods in favour of China in 2014. It is worth noting that the most central country in terms of preferences at the world level in most cases is different from the most central country within its own region, as it happens for the Netherlands. This can occur when a country plays the role of a bridge between important trading areas.

Some of the above results might seem counter-intuitive, but it should be reminded that our networks of preferential trade are binary, meaning that they represent the topology of trade preferences in terms of their extensive margin. More precisely, they refer to the number of revealed trade preferences, regardless of their intensity. So, a country can appear as more central than another not only because of its importance as a hub of international production networks, but also as a result of a relatively high number of weak preferential trade linkages.

Overall, the correlation between the topological indicators of our networks of preferential trade for intermediate goods and for consumption goods is high across regions and over time, especially for the simplest indices (density, clustering), suggesting that what drives trade preferentiality for the two types of goods might often be the same country characteristics. However, such similarity in topological properties is much lower when considering the higher-order properties of the networks for intermediate and consumption 


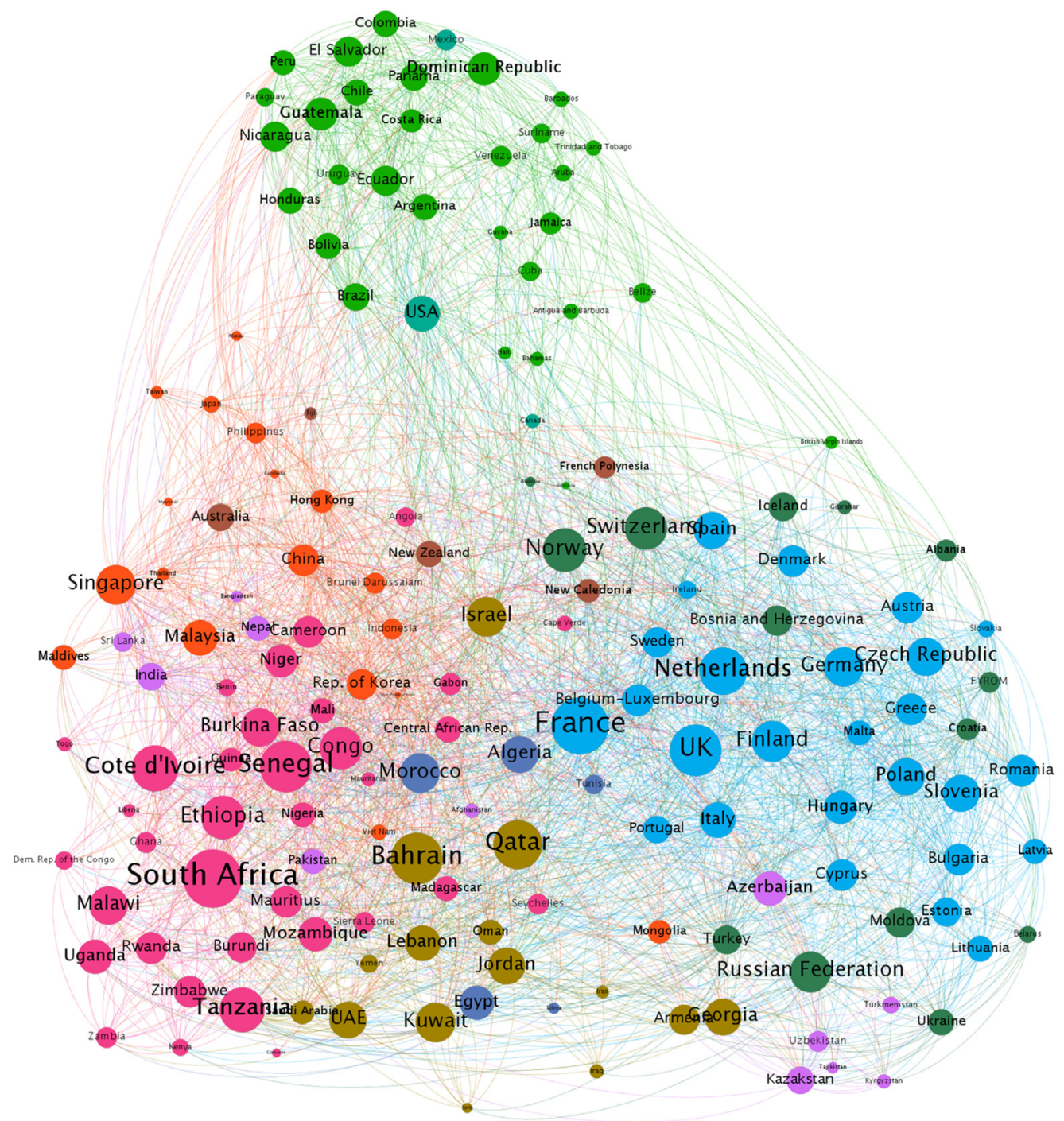

Fig. 10. Network of preferential trade in Electronics in 2014 - Consumption goods (Source: our elaboration on COMTRADE database).

goods, suggesting a different organization of trade flows for the different goods categories.

\section{Conclusions}

In this work, by analysing trade preferences in two industries strongly involved in global production networks, we wanted to address two main questions: whether preferential trade links in different goods categories are still mainly regional (assuming that distance is still very relevant especially to coordinate production), and whether the structure of preferential trade links provides information on the structure of existing IPNs.

To do this, we applied and compared two sets of analytical tools. Both revealed trade preference indices and network analysis of such preferences confirm that the patterns of trade in final goods and in intermediate goods are different, even if not in a dramatic way. Both analyses have shown also that regionalization is still high, especially in electronics, but it has slightly declined in the recent past. Moreover, there are some relevant links bridging different neighbouring regions.

The observed pattern can also be related to the presence of trade agreements with different characteristics and different depth. Many preferential and regional trade agreements include specific provisions that facilitate participation to IPNs and trade in intermediates by setting common rules and standards (see Orefice and Rocha, 2014), and this might have slowed down in some cases the full globalization of production processes.

Both analyses also show significant differences between industries, which could be related to diversities in the technological characteristics of the goods and in the organization of production. There are no general trends in IPNs, as changes seem to be sector- 


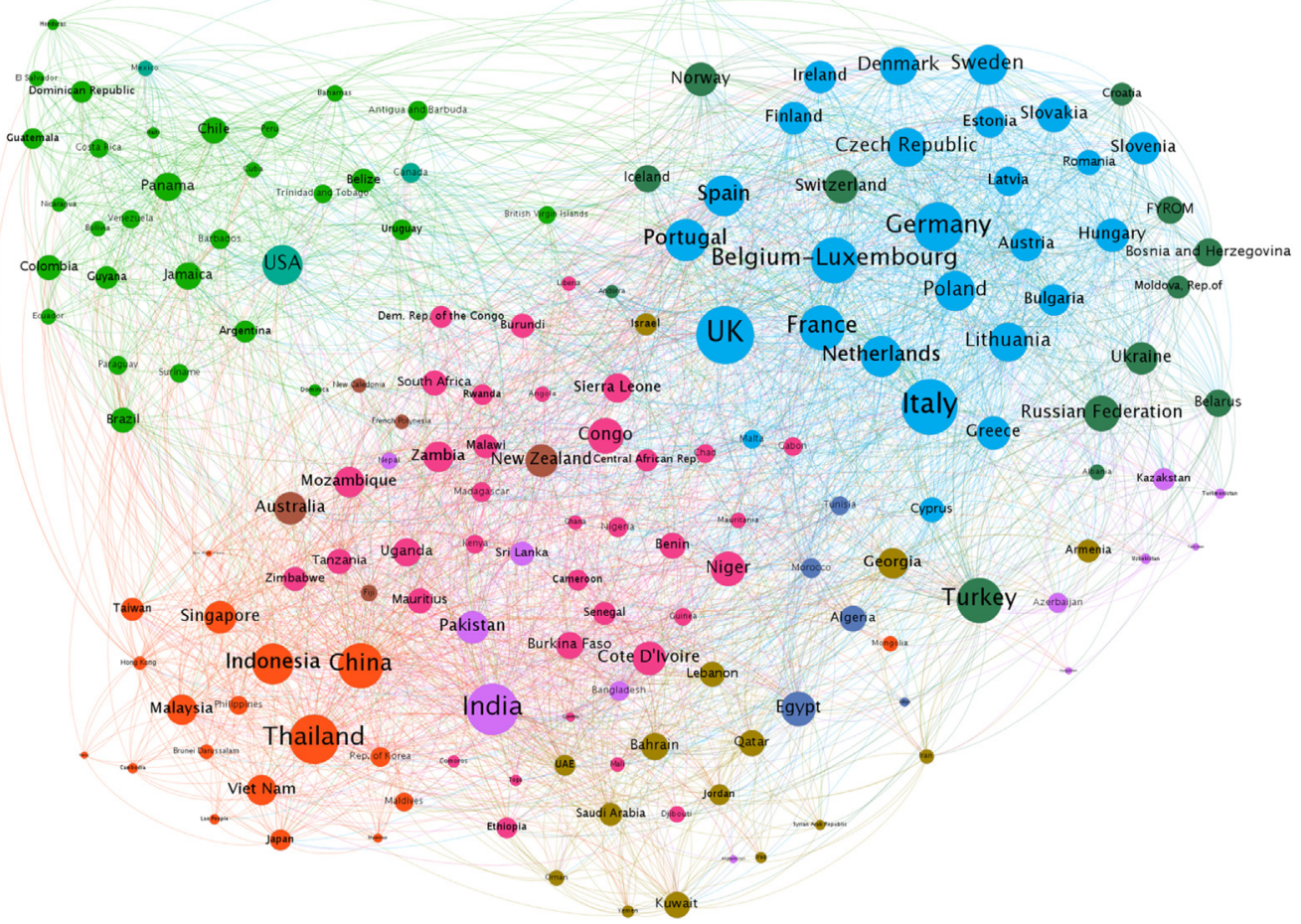

Fig. 11. Network of preferential trade in Textiles in 2014 - Intermediate goods (Source: our elaboration on COMTRADE database).

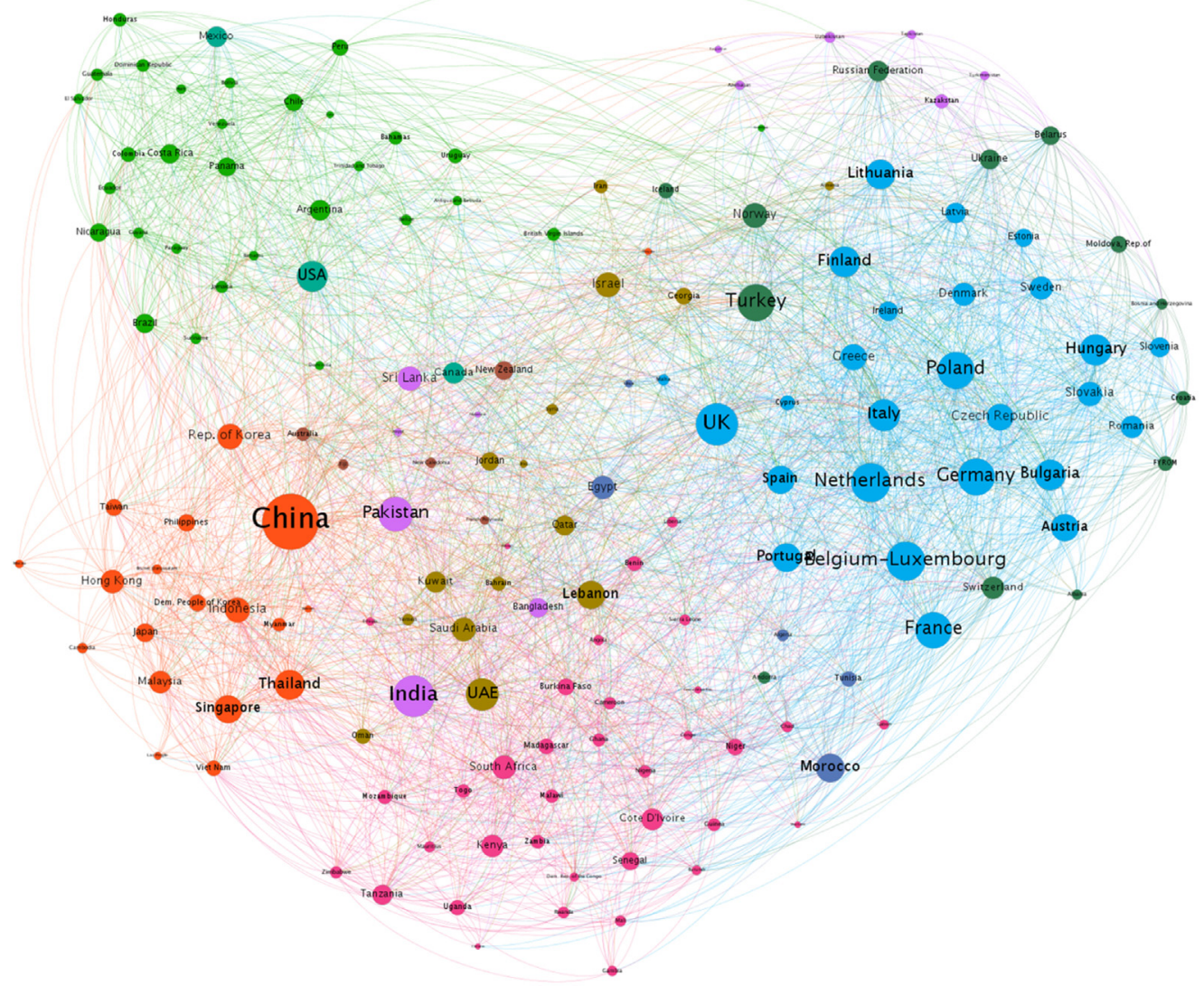

Fig. 12. Network of preferential trade in Textiles in 2014 - Consumption goods (Source: our elaboration on COMTRADE database). 
Table 4

Topology of the network of trade preferences: Electronic goods Preferential links $(0>\mathrm{RTP}(\mathrm{ij})>1)$

\begin{tabular}{|c|c|c|c|c|c|c|c|c|c|c|c|c|c|c|}
\hline & \multicolumn{7}{|l|}{2007} & \multicolumn{7}{|l|}{2014} \\
\hline & $\begin{array}{l}\text { Number of } \\
\text { connected } \\
\text { nodes }\end{array}$ & Density & Clustering & $\begin{array}{l}\text { Assortativity_ } \\
\text { outdegree_ } \\
\text { indegree }\end{array}$ & $\begin{array}{l}\text { Assortativity_ } \\
\text { indegree_ } \\
\text { outdegree }\end{array}$ & $\begin{array}{l}\text { Centralization_ } \\
\text { in_degree }\end{array}$ & $\begin{array}{l}\text { Centralization_ } \\
\text { out_degree }\end{array}$ & $\begin{array}{l}\text { Number of } \\
\text { connected } \\
\text { nodes }\end{array}$ & Density & Clustering & $\begin{array}{l}\text { Assortativity_ } \\
\text { outdegree_ } \\
\text { indegree }\end{array}$ & $\begin{array}{l}\text { Assortativity_ } \\
\text { indegree_ } \\
\text { outdegree }\end{array}$ & $\begin{array}{l}\text { Centralization_ } \\
\text { in_degree }\end{array}$ & $\begin{array}{l}\text { Centralization } \\
\text { out_degree }\end{array}$ \\
\hline \multicolumn{15}{|l|}{ Total trade } \\
\hline World & 165 & 0.164 & 0.359 & -0.088 & -0.017 & 0.248 & 0.490 & 163 & 0.164 & 0.352 & -0.107 & -0.021 & 0.196 & 0.432 \\
\hline European Union & 26 & 0.657 & 0.746 & -0.058 & -0.067 & 0.189 & 0.266 & 26 & 0.691 & 0.783 & -0.097 & -0.039 & 0.194 & 0.271 \\
\hline Other European Countries & 14 & 0.332 & 0.493 & 0.011 & -0.045 & 0.168 & 0.311 & 14 & 0.357 & 0.575 & -0.120 & 0.003 & 0.214 & 0.429 \\
\hline North Africa & 5 & 0.560 & 0.711 & -0.458 & -0.027 & 0.240 & 0.240 & 5 & 0.440 & 0.526 & -0.035 & 0.290 & 0.160 & 0.360 \\
\hline Sub-Saharian Africa & 36 & 0.307 & 0.556 & -0.215 & -0.110 & 0.332 & 0.637 & 35 & 0.318 & 0.513 & -0.203 & -0.081 & 0.300 & 0.682 \\
\hline NAFTA & 3 & 0.667 & 1.000 & & & 0.000 & 0.000 & 3 & 0.667 & 1.000 & & & 0.000 & 0.000 \\
\hline Other American Countries & 31 & 0.408 & 0.572 & -0.173 & -0.143 & 0.270 & 0.528 & 30 & 0.374 & 0.548 & -0.187 & -0.074 & 0.314 & 0.556 \\
\hline Middle East & 15 & 0.507 & 0.686 & -0.025 & 0.110 & 0.227 & 0.360 & 15 & 0.427 & 0.518 & -0.081 & -0.026 & 0.307 & 0.373 \\
\hline Central and South Asia & 12 & 0.264 & 0.587 & -0.163 & -0.189 & 0.153 & 0.236 & 12 & 0.229 & 0.627 & -0.588 & -0.415 & 0.188 & 0.271 \\
\hline East Asia & 18 & 0.386 & 0.598 & -0.317 & -0.147 & 0.281 & 0.392 & 18 & 0.389 & 0.542 & -0.297 & -0.162 & 0.278 & 0.389 \\
\hline Oceania & 5 & 0.680 & 0.853 & -0.181 & 0.029 & 0.120 & 0.120 & 5 & 0.680 & 0.878 & -0.443 & -0.244 & 0.120 & 0.120 \\
\hline \multicolumn{15}{|l|}{ Intermediates } \\
\hline World & 165 & 0.159 & 0.368 & -0.118 & -0.051 & 0.241 & 0.556 & 163 & 0.159 & 0.370 & -0.143 & -0.031 & 0.213 & 0.487 \\
\hline European Union & 26 & 0.615 & 0.731 & -0.098 & -0.058 & 0.231 & 0.308 & 26 & 0.691 & 0.793 & -0.080 & -0.048 & 0.194 & 0.232 \\
\hline Other European Countries & 13 & 0.361 & 0.475 & -0.047 & -0.080 & 0.302 & 0.385 & 14 & 0.332 & 0.572 & -0.187 & -0.174 & 0.168 & 0.383 \\
\hline North Africa & 5 & 0.600 & 0.778 & -0.452 & -0.004 & 0.200 & 0.200 & 5 & 0.400 & 0.529 & 0.118 & 0.114 & 0.200 & 0.200 \\
\hline Sub-Saharian Africa & 36 & 0.235 & 0.510 & -0.263 & -0.133 & 0.349 & 0.682 & 35 & 0.246 & 0.495 & -0.243 & -0.139 & 0.342 & 0.753 \\
\hline NAFTA & 3 & 0.667 & 1.000 & & & 0.000 & 0.000 & 3 & 0.667 & 1.000 & & & 0.000 & 0.000 \\
\hline Other American Countries & 31 & 0.357 & 0.573 & -0.174 & -0.094 & 0.224 & 0.579 & 30 & 0.333 & 0.554 & -0.195 & -0.103 & 0.287 & 0.631 \\
\hline Middle East & 15 & 0.498 & 0.681 & -0.023 & 0.067 & 0.236 & 0.369 & 15 & 0.387 & 0.505 & -0.079 & -0.081 & 0.347 & 0.347 \\
\hline Central and South Asia & 12 & 0.285 & 0.674 & -0.348 & -0.205 & 0.049 & 0.215 & 12 & 0.229 & 0.547 & -0.590 & -0.318 & 0.188 & 0.271 \\
\hline East Asia & 18 & 0.349 & 0.568 & -0.335 & -0.148 & 0.262 & 0.373 & 18 & 0.343 & 0.550 & -0.404 & -0.152 & 0.213 & 0.269 \\
\hline Oceania & 5 & 0.640 & 0.867 & -0.548 & -0.548 & 0.160 & 0.160 & 5 & 0.680 & 0.878 & -0.443 & -0.244 & 0.120 & 0.120 \\
\hline \multicolumn{15}{|l|}{ Consumer Goods } \\
\hline World & 165 & 0.121 & 0.304 & -0.163 & -0.054 & 0.109 & 0.352 & 163 & 0.111 & 0.294 & -0.146 & -0.073 & 0.150 & 0.342 \\
\hline European Union & 26 & 0.550 & 0.613 & -0.106 & -0.089 & 0.180 & 0.334 & 26 & 0.530 & 0.610 & -0.002 & -0.031 & 0.201 & 0.278 \\
\hline Other European Countries & 14 & 0.235 & 0.281 & 0.058 & -0.073 & 0.194 & 0.265 & 14 & 0.276 & 0.484 & -0.028 & 0.159 & 0.224 & 0.367 \\
\hline North Africa & 5 & 0.520 & 0.662 & -0.020 & 0.063 & 0.280 & 0.080 & 5 & 0.280 & 0.310 & -0.333 & -0.105 & 0.120 & 0.320 \\
\hline Sub-Saharian Africa & 36 & 0.167 & 0.507 & -0.240 & -0.046 & 0.222 & 0.750 & 35 & 0.205 & 0.496 & -0.256 & -0.104 & 0.324 & 0.647 \\
\hline NAFTA & 3 & 0.556 & 0.833 & -0.250 & 0.167 & 0.111 & 0.111 & 3 & 0.556 & 0.833 & -0.250 & 0.167 & 0.111 & 0.111 \\
\hline Other American Countries & 31 & 0.296 & 0.585 & -0.200 & -0.023 & 0.382 & 0.575 & 30 & 0.282 & 0.481 & -0.091 & -0.056 & 0.338 & 0.407 \\
\hline Middle East & 15 & 0.449 & 0.612 & -0.133 & 0.043 & 0.151 & 0.418 & 15 & 0.387 & 0.530 & -0.154 & -0.032 & 0.347 & 0.347 \\
\hline Central and South Asia & 12 & 0.146 & 0.344 & -0.556 & -0.216 & 0.104 & 0.271 & 12 & 0.153 & 0.305 & -0.475 & -0.313 & 0.097 & 0.181 \\
\hline East Asia & 18 & 0.358 & 0.599 & -0.265 & -0.187 & 0.198 & 0.475 & 18 & 0.380 & 0.611 & -0.369 & -0.190 & 0.343 & 0.343 \\
\hline Oceania & 5 & 0.560 & 0.658 & -0.213 & -0.117 & 0.240 & 0.240 & 5 & 0.560 & 0.811 & -0.261 & -0.120 & 0.040 & 0.240 \\
\hline
\end{tabular}

Source: our elaboration on UN Comtrade database. 
Table 5

Topology of the network of trade preferences: Textile goods Preferential links $(0>\operatorname{RTP}(\mathrm{ij})>1)$

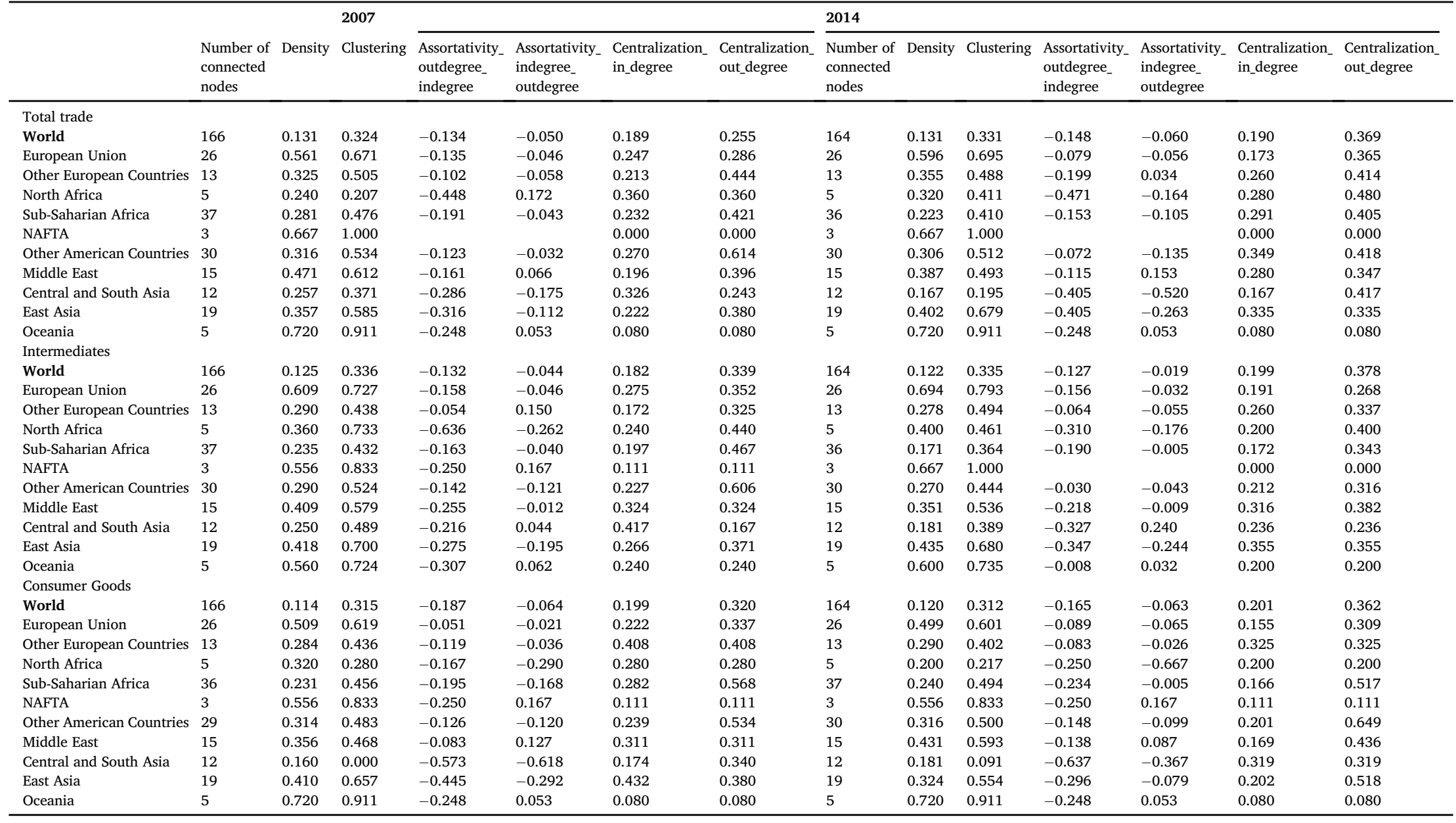

Source: our elaboration on UN Comtrade database. 
specific.

A stronger preferentiality and selection of trade partners seem to occur for trade in intermediate goods, as suggested by the theory of international fragmentation of production, confirming that the topology of trade networks can indeed shed some light on the structure of the underlying production linkages.

\section{Annex 1. Country classification}

\section{European Union}

Austria, Belgium-Luxembourg, Bulgaria, Cyprus, Czech Republic, Denmark, Estonia, Finland, France, Germany, Greece, Hungary, Ireland, Italy, Latvia, Lithuania, Malta, Netherlands, Poland, Portugal, Romania, Slovakia, Slovenia, Spain, Sweden, United Kingdom.

Other European countries

Albania, Andorra, Bosnia and Herzegovina, Belarus, Croatia, Gibraltar, Iceland, Moldova, Norway, Russian Federation, Switzerland, Turkey, Ukraine, The former Yugoslav Rep. of Macedonia.

North Africa

Algeria, Libyan Arab Jamahiriya, Morocco, Tunisia, Egypt.

Sub-Saharan Africa

Angola, Burundi, Cameroon, Cape Verde, Central African Republic, Comoros, Congo, Democratic Republic of the Congo, Benin, Ethiopia, Gabon, Ghana, Guinea, Côte d'Ivoire, Kenya, Liberia, Madagascar, Malawi, Mali, Mauritania, Mauritius, Mozambique, Niger, Nigeria, Rwanda, Senegal, Seychelles, Sierra Leone, South Africa, Zimbabwe, Sudan, ${ }^{9}$ Togo, Uganda, Tanzania, Burkina Faso, Zambia.

North American Free Trade Agreement (NAFTA)

Canada, Mexico, United States of America.

Other American countries

Antigua and Barbuda, Argentina, Bahamas, Barbados, Bolivia, Brazil, Belize, British Virgin Islands, Chile, Colombia, Costa Rica, Cuba, Dominica, Dominican Republic, Ecuador, El Salvador, Guatemala, Guyana, Haiti, Honduras, Jamaica, Netherland Antilles, ${ }^{10}$ Aruba, Nicaragua, Panama, Paraguay, Peru, Suriname, Trinidad and Tobago, Uruguay, Venezuela.

Middle East

Bahrain, Armenia, Georgia, Iran (Islamic Republic of), Iraq, Israel, Jordan, Kuwait, Lebanon, Oman, Qatar, Saudi Arabia, Syrian Arab Republic, United Arab Emirates, Yemen.

Central and South Asia

Afghanistan, Azerbaijan, Bangladesh, Sri Lanka, Kazakstan, Kyrgyzstan, Nepal, Pakistan, India, Tajikistan, Turkmenistan, Uzbekistan.

East Asia

Brunei Darussalam, Myanmar, Cambodia, China, Hong Kong (SARC), Indonesia, Japan, Korea (Dem. People's Rep. of), Korea (Rep. of Korea), Lao People's Democratic Republic, ${ }^{11}$ Macau, Malaysia, Maldives, Taiwan (Province of China), Mongolia, Philippines, Singapore, Viet Nam, Thailand.

Oceania

Australia, Fiji, French Polynesia, New Caledonia, New Zealand.

\section{Annex 2. Revealed trade preference indices ${ }^{12}$}

Revealed trade preference indices are a particular specification of statistical indicators aimed at measuring the intensity of bilateral trade. Trade intensity indices are based on a comparison between actual bilateral trade flows and the hypothetical value they would reach in a situation of geographic neutrality, namely if the reciprocal importance of each country were equal to its weight in world trade (Kunimoto, 1977). In other words, given the trade size of the two countries, which depends on both their economic size and their degree of international openness, bilateral trade intensity indices aim at capturing the degree of reciprocal preference between two trading partners, which can be the result of geographic nearness and/or other proximity factors. Referring to a geographic neutrality threshold implies that proximity is implicitly defined in relative terms, as the ratio between bilateral distance and the average distance from the other countries.

The variance of bilateral intensity indices around their neutrality benchmark may be seen as a measure of the combined effect of relative distances and other factors hindering (or facilitating) bilateral trade. An abstract world in which the variance of intensity indices is zero may be taken as a benchmark of full globalization: a 'frictionless' world in which distance and other barriers or proximity factors do not affect the geography of trade. ${ }^{13}$

\footnotetext{
${ }^{9}$ The filtering procedure has excluded Sudan in 2014.

${ }^{10}$ The filtering procedure has excluded the Netherland Antilles in 2014.

${ }^{11}$ The filtering procedure has excluded Lao only for the network analysis of the electronics industry.

12 This Annex is largely drawn from Iapadre and Tajoli (2014).

13 A less demanding benchmark could be obtained through distance-adjusted intensity indices, following the logical framework of the gravity model of international trade. See De Lombaerde and Iapadre (2008).
} 
Intensity indices have also been used to measure trade regionalization, that is the tendency of countries belonging to the same region to trade relatively more between each other (intra-regional trade) than with the rest of the world (inter-regional trade). ${ }^{14}$

As shown by gravity models, the variable size of a country's possible partners is the most important determinant of the geographic distribution of its bilateral trade flows. Therefore, bilateral trade shares of different partners are strongly (and trivially) correlated with their total trade size. Trade intensity indices are aimed at correcting for this problem by giving a size-independent measure of the strength of bilateral trade linkages.

In its simplest and most widely used form, which is a geographic equivalent of the well-known Balassa (1965) index of revealed comparative advantages, a bilateral trade intensity index $\left(I_{i j}\right)$ is equal to the ratio between a partner country's share of the reporting country's total trade $\left(S_{i j}\right)$ and its share of world trade $\left(W_{j}\right)$ :

$$
I_{i j}=S_{i j} / W_{j}=\left(T_{i j} / T_{i w}\right) /\left(T_{w j} / T_{w w}\right)
$$

where:

$T_{i j}$ : trade (exports plus imports) between reporting country $i$ and partner country $j$;

$T_{i w}$ : trade between reporting country $i$ and the world; $T_{w j}$ : world trade with country $j ; T_{w w}$ : total world trade.

So, bilateral intensity indices are equal to one if the geographic distribution of a country's trade flows is proportional to the trade size of its partners (geographic neutrality). ${ }^{15}$

Bilateral trade intensity indices are affected by at least three problems, which limit their usefulness: their range is not homogeneous across partner countries (range variability) and is asymmetric around the geographic neutrality threshold of one (range asymmetry), and their changes over time can be difficult to interpret (dynamic ambiguity). ${ }^{16}$

Range variability is shown by the fact that $0 \leq I_{i j} \leq\left(1 / W_{j}\right)$. In other words, the maximum value of the index, which is reached when country $j$ is the only partner of country $i$, is a decreasing function of the partner country's total trade, so that indices computed for different countries and/or periods are not perfectly comparable among each other.

The problem of range variability has been addressed, among others, by Anderson and Norheim (1993). A possible solution is offered by a 'homogeneous' bilateral trade intensity index $\left(H I_{i j}\right)$, given by the ratio between a partner country's share of the reporting country's total trade $\left(S_{i j}\right)$ and its weight in total trade of the rest of the world $\left(V_{i j}\right)$ :

$$
H I_{i j}=S_{i j} / V_{i j}=\left(T_{i j} / T_{i w}\right) /\left(T_{o j} / T_{o w}\right)
$$

where:

$T_{o j}$ : trade between the rest of the world (excluding country $i$ ) and country $j$;

$T_{\text {ow }}$ : trade between the rest of the world and the world.

The range of $\mathrm{HI}_{i j}$ goes from zero (no bilateral trade) to infinity (only bilateral trade) with a geographic neutrality threshold of one, when the importance of country $j$ for country $i$ is equal to its weight in world trade. Unlike the traditional Balassa index, $H_{i j}$ is homogeneous in the sense that its maximum value does not depend on the size of the partner country.

However, both indices are asymmetric around their geographic neutrality threshold. The range below the threshold value of one is much smaller than above, which may give rise to biased assessments of the index changes, and create problems in econometric estimates involving the index.

The dynamic ambiguity problem of $\mathrm{HI}_{i j}$ is that, under certain conditions, ${ }^{17}$ its changes over time can have the same sign as the changes of the complementary 'extra-bilateral' trade intensity index $H E_{i j}$, which measures the intensity of trade relations between country $i$ and all the other countries except country $j$ :

$$
H E_{i j}=\left(1-S_{i j}\right) /\left(1-V_{i j}\right)
$$

When this problem occurs, interpreting the indices becomes difficult and confusing, because they convey the ambiguous information that trade intensity is increasing (or decreasing) simultaneously with country $j$ and with the rest of the world, which would be an oxymoron.

A possible joint solution for the range asymmetry and dynamic ambiguity problems is to consider the ratio between the difference and the sum of $H I_{i j}$ and $H E_{i j}$ as an indicator of relative bilateral trade intensity. In Iapadre and Tironi (2009) this ratio has been defined as the bilateral revealed trade preference index $\left(R T P_{i j}\right)$ :

$$
R T P_{i j}=\left(H I_{i j}-H E_{i j}\right) /\left(H I_{i j}+H E_{i j}\right)
$$

This index ranges from minus one (no bilateral trade) to one (only bilateral trade) and is equal to zero in the case of geographic neutrality.

An additional property of the bilateral RTP index is that, unlike trade intensity indices, it is perfectly symmetric across partner

\footnotetext{
14 See Iapadre and Plummer (2011).

${ }^{15}$ A slight distortion in the geographic neutrality criterion is due to the fact that the set of partner countries changes across reporting countries, since by definition no country can trade with itself. This problem, raised by Savage and Deutsch (1960), requires some adjustments in the formulas, similar to those described by Anderson and Norheim (1993: 82, footnote 6). A more rigorous correction procedure can be found in Freudenberg, Gaulier and Ünal-Kesenci (1998).

16 These problems have been analyzed by Iapadre (2006) with particular reference to intra-regional trade intensity indices.

17 See Iapadre (2006:: 70-1).
} 
countries, in the sense that:

$$
R T P_{i j}=R T P_{j i}
$$

independently of country size.

$R T P$ indices can also be used to map the intensity of trade within a region $r$. For each of its member countries, intra-regional revealed trade preferences can be computed simply by applying the above formulas to the country's trade with the rest of the region, treated as a single partner.

$$
R T P_{i r}=R T P_{r i}=\left(H I_{i r}-H E_{i r}\right) /\left(H I_{i r}+H E_{i r}\right)
$$

It can be shown that $H_{i r}$ is the weighted average of the corresponding bilateral indices between country $i$ and its regional partners, with weights given by the relative trade size of country $i$ 's partners for the rest of the world $\left(V_{i j} / \Sigma_{j: i t} V_{i j}\right)$.

An intra-regional RTP index $\left(R T P_{r r}\right)$ can be computed also for the region as a whole, and is equivalent to the 'regional trade introversion' index proposed by Iapadre (2006). It measures in relative terms to what extent a region's member countries tend to trade among each other more intensively than with third countries. This is often the result not so much of a high degree of regional integration as of structural problems limiting the region's members' ability to participate in the international trade network.

For any given level of regional introversion, bilateral trade flows among member countries and with the rest of the world may exhibit different patterns, reflecting several factors, such as differences in country size, degree of openness and relative distance. Possible hierarchical structures within the regional trade network may also influence the level of bilateral trade. For example, in a 'huband-spoke' network, the importance of the 'hub' country for the rest of the region (the spokes) is greater than the importance of the spokes for the hub, which tends to be more oriented towards the rest of the world.

However, these leadership structures cannot be captured if the RTP indices are computed on the value of bilateral trade (exports plus imports). In this case, RTP indices, unlike trade intensity indices, preserve the bilateral symmetry property of trade values, so that the importance of the hub for the spokes is by definition equal to the importance of the spokes for the hub.

Conversely, bilateral symmetry does not emerge if the matrix refers only to exports or imports. If we define revealed import and export preference indices as:

$$
\begin{aligned}
& R M P_{i j}=\left(H M I_{i j}-H M E_{i j}\right) /\left(H M I_{i j}+H M E_{i j}\right) \\
& R X P_{i j}=\left(H X I_{i j}-H X E_{i j}\right) /\left(H X I_{i j}+H X E_{i j}\right)
\end{aligned}
$$

where $H M I_{i j}, H M E_{i j}, H X I_{i j}$ and $H X E_{i j}$ are the homogeneous import and export intensity indices built applying formulas [2] and [3] to import and export data, it is generally true that:

$$
\left(R M P_{i j} \equiv R X P_{j i}\right) \neq\left(R M P_{j i} \equiv R X P_{i j}\right)
$$

So, a country's intra-regional RMP is normally different from its intra-regional RXP. This is not the trivial result of bilateral trade imbalances, as the asymmetry would emerge even if the country's imports from the region were equal to its intra-regional exports. The gap between $R M P_{\text {ir }}$ and $R X P_{\text {ir }}$ reflects the different relative importance of each partner in imports and exports, taking the intensity of trade with the rest of the world into account.

\section{Annex 3. Network visualization graphs}

Networks depicted in Figs. 9-12 have been produced using the network visualization software Gephi@, and in particular its default layout algorithm, called ForceAtlas2 (Jacomy et al., 2014).

In these figures, the size of nodes is proportional to the count of their inward links, whereas the edges among nodes refer to both outward and inward links. For unweighted networks, it is conventional to attribute unitary weight to all the links.

The ForceAtlas2 algorithm determines the position of each node in the graph considering all the other nodes, simulating a physical system driven by attraction and repulsion forces. The process of placing each node depends only on their reciprocal connections and the final result varies according to the initial state. Possible exogenous or endogenous attributes of the nodes are not taken into account in their placing. So, the position of each node cannot be interpreted on its own, but needs to be compared to the others, depending on the whole structure of connections.

In our case, applied to a directed binary network where each link has equal weight, the interplay of the custom attraction and repulsion forces at the basis of the algorithm is limited to repulsion forces, measured as the product of the degrees of each couple of nodes. In our networks ForceAtlas2 produces visual densities that denote structural densities or communities. In other words, groups of nodes interacting between each other more than with the rest of the network (communities) tend to be revealed by the fact that their nodes are located relatively close to each other. In this way, the spatial distribution of trade preferences is determined endogenously, independently on any a priori geographical classification. Figs. 9-12 allow to easily compare these endogenous preferential regions with geographical clusters used in our analysis, since the colour of each node denotes the region it belongs to. 


\section{Annex 4. Description of network-based indicators}

Number of actual nodes

$N_{r}$ : Count of nodes (countries) within a regional network $r$

Number of actual internal links

$L_{r r}$ : Count of directed links connecting nodes (countries) within a regional network $r$

\section{Number of external links}

$L_{r R o W}$ : Count of directed links connecting nodes (countries) constituting a regional network $r$ to nodes (countries) constituting the rest of the world (RoW).

\section{Density}

$D_{r}$ : The ratio between the actual number of links connecting the $N_{r}$ nodes within a regional network $L_{r r}$ and the corresponding theoretical maximum number of directed links connecting them

$$
L_{r r}^{\max }=N_{r}\left(N_{r}-1\right)
$$

\section{Global clustering coefficient}

$C C_{r}$ : The global clustering coefficient of a regional sub-network $r$ is defined as the average local clustering coefficient of the nodes members of $r$. The local clustering coefficient $c c_{i}$ of a node $i$ is usually computed considering the undirected and binary version of any network and it is defined as the ratio between the number of actual triangles $t_{i}$ connecting node $i$ 's neighbors $n_{i}$ and the theoretical maximum number of triangles $t_{i}^{\max }=n_{i}\left(n_{i}-1\right) / 2$.

Degree centralization

The centralization of any kind of network-based centrality measure is defined as the ratio between 1) the sum of all differences between the centrality score of the most central node(s) and those of all other nodes and 2) the maximum theoretical sum of such differences (Freeman, 1978). It provides insights about the structural organization of links around the most central nodes constituting a network.

Given a certain centrality measure of a node $c_{i}$, the centralization of a network is defined as

$$
C_{r}^{*}=\frac{\sum_{i=1}^{N_{r}}\left|c^{*}-c_{i}\right|}{\max \sum_{i=1}^{N_{r}}\left|c^{*}-c_{i}\right|}
$$

Where $c^{*}$ is the centrality of the most central node in the network and $\max \sum_{i \in r}\left|c^{*}-c_{i}\right|$ is the maximum possible sum of differences in nodes centrality for a network of $N_{r}$ nodes. We chose as centrality measures the total number of direct neighbors of a node or its total degree, the number of a node's direct neighbors connected via outward links or its out-degree and finally the number of a node's direct neighbors connected via inward links or its in-degree.

\section{Degree assortativity}

Assortativity is a graph metric (Newman, 2002) used to measure to what extent nodes in a network associate with "similar" other nodes in the network. Here the assortativity of a network is determined for the degree (number of direct neighbors) of the nodes in the network. It is computed as the linear correlation between two random variables, the nodes degrees and the average degree of the nodes' direct neighbors. We computed assortativity measures using four different combinations of degree definitions, according to the direction of links connecting nodes to their neighbors (in-degree/out-degree assortativity, in-degree/in-degree, out-degree/out-degree assortativity, out-degree/in-degree assortativity).

\section{References}

Anderson, K., Norheim, H., 1993. From imperial to regional trade preferences: its effect on Europe's intra- and extra-regional trade. Weltwirtschaftliches Archiv 129, 78-102.

Arndt, S., Kierzkowski, H., 2001. Fragmentation: New Production Patterns in the World Economy. Oxford University Press, Oxford. 
Antràs, P., Helpman, E., 2004. Global sourcing. J Polit. Econ. 112 (3), 552-580.

Balassa, B., 1965. Trade Liberalisation and Revealed Comparative Advantage, 33. The Manchester School, pp. 99-123.

Baldone, S., Sdogati, F., Tajoli, L., 2001. Patterns and determinants of international fragmentation of production: evidence from outward processing trade between the

EU and Central Eastern European countries. Weltwirtschaftliches Arch 137 (1), 80-104.

Baldwin, R., Lopez Gonzalez, J., 2015. Supply-chain trade: a portrait of global patterns and several testable hypotheses. World Econ 38, 1682-1721.

Baldwin, Richard, 2011. Trade and industrialisation after globalisation's 2nd unbundling: how building and joining a supply chain are different and why it matters, NBER Working Papers 17716, National Bureau of Economic Research, Inc.

Carvalho, V.M., 2014. From micro to macro via production networks. J. Econ. Perspect. 28 (4), 23-48.

Cingolani, I., Piccardi, C., Tajoli, L., 2015. Discovering preferential patterns in sectoral trade networks. PLoS ONE 10 (10), e0140951.

Costinot, A., Vogel, J., Wang, S., 2013. An elementary theory of global supply chains. Rev. Econ. Stud. 80 (1), $109-144$.

De Backer K., Miroudot S., 2013. Mapping global value chains, OECD Trade Policy Paper No. 159.

De Benedictis L., Tajoli L., 2010. Comparing international trade networks, Aussenwirtschaft 65.

De Benedictis, L., Tajoli, L., 2011. The world trade network. World Econ 34 (8), 14171454.

De Benedictis, L., Nenci, S., Santoni, G., Tajoli, L., Vicarelli, C., 2014. Network analysis of world trade using the BACI-CEPII dataset. Glob. Econ. J. 14 (3-4), 287-344. http://dx.doi.org/10.1515/gej-2014-0032.

De Lombaerde, P., Iapadre, L., 2008. The world is not flat: implications for the construction of globalization indicators. World Econ. 9, $159-180$.

di Giovanni J., Levchenko A., 2009. Putting the parts together: trade, vertical linkages, and business cycle co-movement, IMF Working paper 09/181.

Drauz, R., 2014. Re-insourcing as a manufacturing-strategic option during a crisis-Cases from the automobile industry. J. Bus. Res. 67 (3), 346-353. http://dx.doi.org/

10.1016/j.jbusres.2013.01.004.

Freeman, Linton C., 1978. Centrality in social networks conceptual clarification. Soc. Netw 1 (3), 215-239.

Feenstra, R.C., Hanson, G.H., 1999. The impact of outsourcing and high technology capital on wages: estimates for the United States 1979-1990. Q. J. Econ. 114 (3), 907-940.

Freudenberg M., Gaulier G., Ünal-Kesenci D., 1998. La régionalisation du commerce international: une évaluation par les intensités bilatérales. CEPII Working Paper n.

98-05, Centre d'Etudes Prospectives et d'Informations Internationales, Paris.

Gaulier G., Zignago S., 2010. BACI: International Trade Database at the Product-Level. The 1994-2007 Version. CEPII Working Paper n. 2010-23, Centre d'Etudes

Prospectives et d'Informations Internationales, Paris.

Grossman, G., Rossi-Hansberg, E., 2008. Trading tasks: a simple theory of offshoring. Am. Econ. Rev. 98 (5), $1978-1997$.

Hanson, G.H., 1996. Economic integration, intra-industry trade, and frontier regions. Eur. Econ. Rev. 40 (3-5), 941-949. http://dx.doi.org/10.1016/00142921(95) 00103-4.

Hanson, G.H., 1998. North American economic integration and industry location. Oxf. Rev. Econ. Policy 14 (2), 30-44. http://dx.doi.org/10.1093/oxrep/14.2.30.

Hanson, G.H., Mataloni, R.J., Slaughter, M.J., 2005. Vertical production networks in multinational firms. Rev. Econ. Stat. 87, 664-678.

Henderson, J., Dicken, P., Hess, M., Coe, N., Yeung, H., 2002. Global production networks and the analysis of economic development. Rev. Int. Polit. Econ. 9, 436-464.

Hummels, D., Ishii, J., Yi, K.-M., 2001. The nature and growth of vertical specialization in world trade. J. Int. Econ. 54 (1), 75-96.

Koopman, R., Wang, Z., Wei, S.J., 2014. Tracing value-added and double counting in gross exports. Am. Econ. Rev. 104 (2), $459-494$.

Iapadre, L., 2006. Regional integration agreements and the geography of world trade: statistical indicators and empirical evidence. In: De Lombaerde, P. (Ed.), Assessment and Measurement of Regional Integration. Routledge, London, pp. 65-85.

Iapadre, L., Plummer, M., 2011. Statistical measures of regional trade integration. In: De Lombaerde, P., Flores, R., Iapadre, L., Schulz, M. (Eds.), The Regional Integration Manual: Quantitative and Qualitative Methods. Routledge, pp. 98-123.

Iapadre, L., Tajoli, L., 2014. Emerging countries and trade regionalization. A network analysis. J. Policy Model. 36S, S89-S110.

Iapadre L., Tironi F., 2009. Measuring Trade Regionalisation: The Case of Asia. UNU-CRIS Working Paper $2009 / 9$.

Jackson, M.O., 2014. Networks in the understanding of economic behaviors. J. Econ. Perspect. 28 (4), 3-22.

Jacomy, M., Venturini, T., Heymann, S., Bastian, M., 2014. ForceAtlas2, a Continous Graph Layout Algorithm for Handy Network Visualization Designed for Gephi Software. PloS One 9 (6), e98679.

Johnson, R., Noguera, G., 2012. Accounting for intermediates: production sharing and trade in value added. J. Int. Econ. 86 (2), $224-236$.

Kimura, F., Ando, M., 2003. Fragmentation and agglomeration matter: japanese multinationals in America and East Asia. N. Am. J. Econ. Financ. 14, $287-317$.

Kunimoto, K., 1977. Typology of trade intensity indices. Hitotsubashi J. Econ. 17, 15-32.

Los, B., Timmer, M.P., de Vries, G.J., 2015. How global are global value chains? A new approach to measure international fragmentation. J. Reg. Sci. 55, 66-92.

Newman, M.E.J., 2002. Assortative mixing in networks. Phys. Rev. Lett. (89.20, 208701).

Newman, M.E.J., 2003. Mixing patterns in networks. Phys. Rev. E 67, 026126.

Ng, E.C.Y., 2010. Production fragmentation and business-cycle comovement. J Int Econ 82 (1), 1-14.

Nunn, N., 2007. Relationship-specificity, incomplete contracts, and the pattern of trade. Q. J. Econ. 122 (2), 569-600.

Orefice, G., Rocha, N., 2014. Deep integration and production networks: an empirical analysis. World Econ. 37, 106-136. http://dx.doi.org/10.1111/twec.12076.

Savage, I.R., Deutsch, K.W., 1960. A statistical model of the gross analysis of transaction flows. Econometrica 28, 551-572.

Spencer, B.J., 2005. International outsourcing and incomplete contracts. Can. J. Econ. 38 (4), 1107-1135.

Timmer, Marcel P., Erumban, Abdul Azeez, Los, Bart, Stehrer, Robert, de Vries, G.J., 2014. Slicing up global value chains. J. Econ. Perspect. 28 (2), 99-118.

Timmer, M.P., Los, B., Stehrer, R., de Vries, G.J., 2016. An Anatomy of the Global Trade Slowdown based on the WIOD 2016 Release (GGDC Research Memoranda; No. 162). University of Groningen.

Vega Redondo, F., 2007. Complex Social Networks. Cambridge University Press, New York.

Yeung, H.W., Coe, N.M., 2015. Toward a dynamic theory of global production networks. Econ. Geogr. 91 (1), 29-58. http://dx.doi.org/10.1111/ecge.12063. 